\title{
LA EVALUACIÓN DURANTE: EL CORAZÓN DE LAS POLÍTICAS PÚBLICAS HACIA UN MODELO GENERAL PARA LA CREACIÓN DE POLÍTICAS PÚBLICAS
}

\author{
EVALUATION DURING: THE HEART OF PUBLIC POLICIES TOWARDS A \\ GENERAL MODEL FOR THE CREATION OF PUBLIC POLICIES
}

\author{
AVALIAÇÃO DURANTE: O CORAÇÃO DAS POLÍTICAS PÚBLICAS PARA UM \\ MODELO GERAL DE CRIAÇÃO DE POLÍTICAS PÚBLICAS
}

\author{
MANuel Ángel Rodríguez EdezA \\ https://orcid.org/0000-0002-2537-8339 / maredezasinaloa@hotmail.com
}

Universidad Autónoma de Occidente - México

\begin{abstract}
RESUMO
Este trabalho propõe a inclusão de um elemento considerado essencial nas políticas públicas: avaliação durante o processo de implementação, alerta sobre outros problemas que os acompanham e que não foram adequadamente resolvidos, como a correta identificação e delimitação do problema; seu nascimento e gestação; os tempos para o seu desenvolvimento; a falta de participação do cidadão, especialmente em sua construção e implementação, e a própria avaliação. Tomando como referência várias definições e processos, são sugeridos um novo modelo e um novo processo, onde a participação cidadã democrática é essencial. Isso não ocorre regularmente, e são discutidas políticas públicas entre ações governamentais que buscam apenas preservar o poder e não desenvolver o Estado, que deve ser seu principal objetivo. No final, percebe-se que definições multiconceptuais e a infinidade de processos propostos, ao mesmo tempo em que ajudam a enriquecer sua definição, tornaram possível a confusão e a ineficiência.
\end{abstract}

Palavras-chave: Avaliação durante. Orçamento. Particição do cidadão democrata. Políticas públicas. Programação.

\section{ABSTRACT}

This work proposes the inclusion of an element that is considered essential in public policies: evaluation during the implementation process, while warning about other problems that accompany them and that have not been properly resolved, such as the correct identification and delimitation of the problem; its birth and gestation; the times for its development; the lack of citizen participation, especially in its construction and implementation, and the evaluation itself. Taking as reference several definitions and processes, a new model and a new process are suggested, where democratic citizen participation is essential. This does not happen regularly, and public policies are debated between government actions that seek only to preserve power and not to develop the State, which should be its main purpose. In the end, it's possible to see that multiconceptual definitions and the myriad of processes proposed, while helping to enrich their definition, have made confusion and inefficiency possible.

Keywords: Evaluation during. Budgeting. Democratic citizen participation. Public policies. Programming.

\section{RESUMEN}

El presente trabajo propone la inclusión de un elemento que se considera primordial en las políticas públicas: la evaluación durante el proceso de implementación, al tiempo que advertir sobre otros problemas que las acompañan y que no han sido debidamente resueltos como, la identificación y delimitación correcta del problema; su nacimiento y gestación; los tiempos para su desarrollo; la falta de participación ciudadana sobre todo en su construcción e implementación y la propia evaluación. Tomando como referencia un sinnúmero de definiciones y procesos, se sugiere un nuevo modelo y proceso, donde la participación ciudadana democrática, es imprescindible. Regularmente esto no sucede y, las políticas públicas se debaten entre acciones de gobierno que buscan sólo conservar el poder y no desarrollar el Estado cual debiera ser su propósito principal. Al final, se puede observar que las definiciones 
ISSN 1981-3694

(DOI): 10.5902/1981369447071

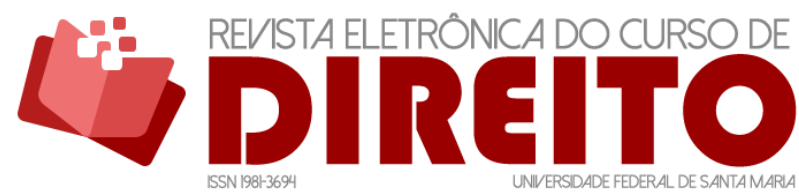

LA EVALUACIÓN DURANTE: EL CORAZÓN DE LAS POLÍTICAS PÚBLICAS HACIA UN MODELO GENERAL PARA LA CREACIÓN DE POLÍTICAS PÚBLICAS

multiconceptuales y el sinnúmero de procesos propuestos, si bien ayudan a enriquecer su definición han posibilitado la confusión y su ineficiencia.

Palabras clave: Evaluación durante. Presupuestación. Participación ciudadana democrática. Políticas públicas. Programación.

\section{SUMÁRIO}

INTRODUCCIÓN; 1 ALGUNAS DEFINICIONES DE POLÍTICAS PÚBLICAS Y SUS ELEMENTOS; 2 LOS CICLOS Y PROCESOS DE LAS POLÍTICAS PÚBLICAS; 3 EL CARÁCTER PÚBLICO DE LAS POLÍTICAS PÚBLICAS Y LA PARTICIPACIÓN CIUDADANA; 4 LOS PROBLEMAS DE LAS POLÍTICAS PÚBLICAS; 5 LA PROGRAMACIÓN; 6 LA EVALUACIÓN; 7 NUESTRA PROPUESTA; 7.1 DEFINICIONES; CONCLUSIONES; REFERENCIAS.

\section{INTRODUCCIÓN}

Hay muchas “lagunas” en un modelo ideal de políticas públicas. Las hay, desde el momento mismo de su gestación, los tiempos de ejecución e identificación. El presente artículo plantea algunas de ellas que considera primordiales; no sin reconocer muchas otras, que también serán señaladas, pero que no serán atendidas a profundidad en el presente trabajo.

En el sentido ideal, las políticas públicas son acciones o inacciones ${ }^{1}$ de gobierno para desarrollar el Estado; en el sentido real, las políticas públicas son acciones de gobierno para conservar el poder. Si es lo primero, derivarán de proyectos de gobierno debidamente pensados, planeados y desarrollados, desde la elección misma incluso del o los candidatos vencedores, fortalecidos posteriormente en los planes formales de quien resulte triunfador precisamente por el veredicto del pueblo que democráticamente y con madurez lo eligió por el proyecto que presentó. De ser así, las políticas públicas se gestarán desde el principio con una de las características que debieran contener y que, es una de las tres condiciones que las hace públicas, la participación en ellas de los gobernados. Posteriormente, ese mandato y esa anuencia, dará el otro carácter público de las políticas, al ser implementadas por éste, el gobierno, con destino final para los ciudadanos, que es la tercera y última condición pública de las políticas. De no ser así, las políticas públicas ya no contarán con una de las condiciones necesarias de su constitución y perderán ese carácter, siendo sólo acciones de gobierno, aunque fueran incluso para desarrollar el Estado. Ahora bien, si las políticas públicas tienen por objeto sólo conservar el poder, ésta primera parte no se obvia, pero se adapta a tales pretensiones abandonándose regularmente una vez que se ha conseguido el objetivo.

\footnotetext{
${ }^{1}$ DYE, Thomas R. Understanding Public Policies. New Jersey: Pearson Prentice Hall, 2008.
} 
Ahora bien, en el contexto ya de su operación, sean para desarrollar el Estado o para conservar el poder, podrán ser de cuatro tipos: Proactivas, esto es, con una visión de Estado o de avanzada; Preventivas, intentando prevenir problemas futuros, de acuerdo a la experiencia pasada; Responsivas, respondiendo a problemas mediatos que se presenten y, Reactivas, reaccionando a problemas urgentes; sólo que en el caso segundo, de conservar el poder, el orden se invierte: reactivas, responsivas, preventivas y proactivas.

Atenderán diferentes etapas y fases, las primeras como dimensiones generales, las segundas, como las acciones que posibilitarán cada una de ellas. En la primera etapa de Nacimiento o Gestación, se incluirá el reconocimiento del problema o situación y su aceptación o no en la agenda; posteriormente su Formulación, que incluye la cabal detección y definición del problema y las posibles alternativas de solución y la selección de la más idónea, vía un análisis FODA y una programación y presupuestación; posteriormente su Aprobación y Legitimación o, el regreso a otras alternativas; después la Implementación y/o ejecución; la Evaluación y Seguimiento o Evaluación Durante y, la Evaluación Final de los resultados, que pretende sancionar si se cumplió o no con el objetivo planteado o en qué medida y, qué faltaría o estaría pendiente por hacerse o continuar.

Ahora bien, todo esto resulta ilusorio, si partiéramos de políticas públicas como ideas para el desarrollo del Estado y no advirtiéramos antes que todo, que derivan precisamente de la política y de quien o quienes la sustenta, no obstante, aún en el peor de los casos, que se tratara de meros asuntos para detentar y conservar el poder, que es válido, pueden lograse por añadidura políticas para desarrollar el Estado, de hecho, muchos países de corte autoritario y hasta dictatoriales, desarrollan políticas satisfactorias para desarrollar al Estado, aunque en un sentido estricto y por lo que se señaló, no podrán revestir carácter de públicas, por no contener de entrada, uno de los elementos esenciales de su carácter público, la participación, libre, consciente y madura de sus gobernados. Aunque se equivocaran.

Es por ello, que partimos del estado ideal de las políticas públicas en este documento, no por ignorar el elemento político que contienen y que incluso le dan sentido y que, ciertamente las pudieran distorsionar, sino porque, atendiendo las causas ideales, se abarcarán también los asuntos convencionales de las políticas estando en condiciones de poder abordarlas, invariablemente. Es decir, el estado ideal de las políticas públicas contiene de algún modo el estado convencional de las políticas públicas.

¿Qué es lo que nos interesa resaltar? ¿Cuáles son los objetivos que se persiguen y perseguimos se puedan alcanzar? Primero, entrar al debate de las políticas públicas y su 
adecuada implementación en la práctica; dos, advertir del estado ideal de las políticas públicas para su desarrollo y tres, bajo ese contexto, exponer sus fallas, particularmente en lo referido en este caso a su programación y evaluación.

La mayoría de los trabajos sobre políticas públicas, derivan regularmente en un análisis de su definición, teorías y/o procesos, incluso de su epistemología, pero ciertamente, “donde más se ha quedado a deber, es su evaluación"2. Las más de las veces no considerada o descrita ex ante (para las alternativas) o ex post (para los resultados) pero no durante, como se propone en el siguiente trabajo, sobre todo en el proceso de implementación.

Para los autores, el éxito de una política pública radica efectivamente en la evaluación acorde del problema, en la detección adecuada y a tiempo de las causas que lo originan y, la selección de la alternativa que se considere más adecuada, en una primera etapa de evaluación de la política; del mismo modo, en la implementación de los indicadores y estándares de medición de los resultados, para una evaluación ex post de la política pero, fundamentalmente, del seguimiento continuo y valoración permanente de esos indicadores durante su proceso, con metas o sub metas escalonadas de medición para los propios indicadores finales; del control oportuno y redirección y/o adecuación de la política, incluso en un momento dado su detención.

Es decir, desde nuestro punto de vista, además de la evaluación ex ante y ex post, que son importantes, interesa la evaluación durante de la política, sea para controlar y/o eficientar los recursos que la posibilitan, como para ir controlando los resultados durante el proceso y no hasta el final, cuando ya no habría mucho que hacer.

Otra parte importante, es la programación, que seguramente se haya implícita para la mayoría de los autores en la formulación o implementación, pero que consideramos necesario, dejarla claramente definida y explícita en el proceso en el lugar que le corresponde o debería corresponder.

En este sentido, se propone, por un lado, la evaluación de las políticas públicas o sus programas durante el proceso, de dos formas, de manera horizontal, para ir supervisando y controlando los resultados y, de manera vertical, para ir controlando los recursos materiales, técnicos, humanos y financieros que la posibiliten. Por otro lado, la programación, que debiera ser, desde nuestro punto de vista desde la formulación de las alternativas y, después, en la implementación, en una reprogramación o afinación de la alternativa seleccionada, según sea el caso y, que ahondaremos más adelante.

\footnotetext{
${ }^{2}$ AGUILAR Astorga, Carlos; LIMA F., Marco Antonio. ¿Qué son y para qué sirven las Políticas Públicas?, en Contribuciones a las Ciencias Sociales, septiembre 2009. Disponible en: www.eumed.net/rev/cccss/05/aalf.htm. Accesado el: 10 jul. 2018. p. 11.
} 
El proceso general identificado por algunos autores ${ }^{3}$, de Gestación, Formulación, Implementación y Evaluación, con variaciones por algunos otros, no está mal, pero debe ser reordenado y reconsiderado, como un proceso de Gestación, Formulación, la programación como un conector con la Implementación y la evaluación ex ante, ex post, pero particularmente durante el proceso, esa es nuestra propuesta.

Para una mejor explicación y comprensión, dividiremos el trabajo en 9 apartados: esta introducción, algunas de las definiciones más importantes sobre políticas públicas, las teorías procesales más socorridas, un apartado sobre el carácter público y la participación ciudadana de las políticas, otro sobre los problemas, un sexto, sobre la programación, un séptimo sobre la evaluación y, finalmente, nuestra propuesta y conclusiones. Se hace hincapié, que ésta es una idea original que pretende ser punto de reconsideración de las políticas públicas no sólo en México, sino de manera general.

\section{ALGUNAS DEFINICIONES DE POLÍTICAS PÚBLICAS Y SUS ELEMENTOS}

Las definiciones sobre políticas públicas comprenden diferentes acepciones y puntos de vista; desde los que hacen énfasis en el elemento político, como los que consideran cuestiones más prácticas, como el elemento administrativo o gubernamental; las hay también, quienes ponen de relieve la participación democrática en su conformación y, otras, que consideran los conflictos entre ideales y valores o de regulación de la sociedad. Tal vez por ello, Antoni Fernández ${ }^{4}$ acierta al decir que no es un fenómeno objetivo y de perfiles claros y definidos, yo diría, tampoco permanentes y únicos (como casi todos los fenómenos de las ciencias sociales); posiblemente lo que es hoy recomendable, no lo será mañana, o dejará de serlo. 0 incluso, lo será para algunos Estados y otros no, aún en el mismo momento. De cualquier modo, delimitar o intentar "encerrar" en un concepto una definición (social), aunque sea para un momento determinado, no está mal, por que posibilita elementos de análisis científicamente hablando y, advierte, sobre cuestiones que debieran ser consideradas, tal vez por ello, se le reconoce a

\footnotetext{
${ }^{3}$ AGUILAR Astorga, Carlos; LIMA F., Marco Antonio. ¿Qué son y para qué sirven las Políticas Públicas?, en Contribuciones a las Ciencias Sociales, septiembre 2009. Disponible en: www.eumed.net/rev/cccss/05/aalf.htm. Accesado el: 10 jul. 2018.

${ }^{4}$ FERNÁNDEZ, Antoni. Las Políticas Públicas. In: CAMINAL, Miguel. Manual de Ciencia Política. Madrid: Tecnos, 1999. p. 460-482.
} 
Harold Laswell ${ }^{5}$, como el padre de la disciplina, al considerar el carácter científico que debieran contener.

En este orden de ideas, y aprovechando el trabajo de algunos autores e investigadores, concretamente Tito Flores Cáceres $^{6}$ y Aguilar y Lima $^{7}$, clasificaremos y caracterizaremos algunas de las definiciones más socorridas e importantes (ver cuadro 1 y cuadros anexos).

Grau $^{8}$; Jenkins ${ }^{9}$; Canto ${ }^{10}$; Roth ${ }^{11}$; y Medellín ${ }^{12}$ abonan al elemento político, al considerar a las políticas públicas asuntos de poder y, como tal, que se dirimen en las esferas políticas. Por su parte, Dye ${ }^{13}$; Meny y Thoening ${ }^{14}$; Tamayo ${ }^{15}$; Laswell ${ }^{16}$; y Brum ${ }^{17}$, entre otros, hacen énfasis en el elemento gubernamental, al considerar que éstas, son invariablemente acciones de gobierno, indistintamente del proceso o los conflictos que hayan seguido. Aguilar Villanueva ${ }^{18}$ por su parte y Jack C. Plano ${ }^{19}$, advierten sobre el carácter eminentemente administrativo de las políticas públicas. El elemento democrático, lo reconocen tácitamente Lahera ${ }^{20}$; Laswell ${ }^{21}$; y Manuel

5 JAIME, Fernando, et al. Introducción al análisis de políticas públicas. Argentina: Universidad Nacional Arturo Jauretche, 2013. p. 85-118. p. 85.

6 FLORES CÁCERES, Tito. Definición de política pública: una revisión conceptual. Disponible en: https://politicapublica.cl/2014/11/10/definicion-de-politica-publica-revision-conceptual/. Accesado el: 8 jun. 2017.

${ }^{7}$ AGUILAR Astorga, Carlos; LIMA F., Marco Antonio. ¿Qué son y para qué sirven las Políticas Públicas?, en Contribuciones a las Ciencias Sociales, septiembre 2009. Disponible en: www.eumed.net/rev/cccss/05/aalf.htm. Accesado el: 10 jul. 2018.

${ }^{8}$ GRAU, Mireia. Introducción. El Estudio de las Políticas Públicas: Enfoques y Metodologías de Análisis. In: M. Grau; A. Mateos. Análisis de Políticas Públicas en España: enfoques y casos, Valencia: Tirant lo Blanch, 2002. p. 29-58.

9 JENKINS, William. Policy Analysis: A Political and Organizational Perspective. London: Martin Robertson, 1978.

10 CANTO, M. Introducción a las políticas públicas. In: Manuel Canto; O. Castro (Orgs). Participación Ciudadana y Políticas Públicas en el Municipio. México: MCD, 2002.

${ }^{11}$ ROTH, A. Políticas Públicas: Formulación, Implementación y Evaluación. Bogotá: Aurora, 2006.

${ }^{12}$ MEDELLIN, P. La política de las políticas públicas: propuesta teórica y metodológica para el estudio de las políticas públicas en países de frágil institucionalidad. Chile: Serie Políticas Sociales, n. 93, 2004.

${ }^{13}$ DYE, Thomas R. Understanding Public Policies. New Jersey: Pearson Prentice Hall, 2008.

${ }^{14}$ MENY, Y.; THOENING, J. Las Políticas Públicas. Barcelona: Editorial Ariel, 1992.

15 TAMAYO Sáenz, Manuel. El análisis de las políticas públicas. In: Rafael Bañón y Ernesto Castillo (Orgs). La nueva administración pública. Madrid: Alianza editorial, 1997. p. 281-312.

${ }^{16}$ LASSWELL, H. La concepción emergente de las ciencias de políticas. In: Luis Aguilar V. El estudio de las políticas públicas. México: Porrúa, 1992. p. 79-117.

17 BRUM, Cardozo M. La evaluación de políticas y programas públicos: el caso de los programas de desarrollo social en México. México: Porrúa, 2006.

${ }^{18}$ AGUILAR Villanueva, L. Estudio Introductorio. In: VILLANUEVA, Luis Aguilar. La Hechura de las Políticas Públicas. México: Miguel Ángel Porrúa, 1996. p. 15-84.

${ }_{19}$ PLANO, Jack C. Political Science Dictionary. Michigan: Dryden Press, 1973.

20 LAHERA, Eugenio. Introducción a las Políticas Públicas. Santiago de Chile: Fondo de Cultura Económica, 2002

${ }^{21}$ LASSWELL, H. La concepción emergente de las ciencias de políticas. In: Luis Aguilar V. El estudio de las políticas públicas. México: Porrúa, 1992. p. 79-117. 
Canto $^{22} \mathrm{y}$, finalmente, en un abanico de definiciones, algunos autores como Kraft y Furlong ${ }^{23}$, Majone $^{24}$, Subirats y Gomá $^{25}$, el propio Canto $^{26}$ y Lindblom $^{27}$, apuntan elementos de valores, lenguaje, regulación e intereses de una sociedad, etcétera, principalmente de la era moderna.

\section{Cuadro 1 - DEFINICIONES SOBRE POLÍTICAS PÚBLICAS (RESUMEN)}

\begin{tabular}{|c|c|c|c|c|c|}
\hline $\begin{array}{l}\text { Concepción/ } \\
\text { Autor }\end{array}$ & Elemento político & $\begin{array}{c}\text { Elemento } \\
\text { gubernamental }\end{array}$ & $\begin{array}{c}\text { Elemento } \\
\text { administrativo }\end{array}$ & $\begin{array}{c}\text { Elemento } \\
\text { democrático }\end{array}$ & Otro \\
\hline $\begin{array}{l}\text { Aguilar } \\
\text { Villanueva }\end{array}$ & & & & & \\
\hline Dye & & $\mathrm{X}$ & & & \\
\hline Fernández & & & & & $\mathrm{X}$ \\
\hline Grau & $\mathrm{X}$ & & & & \\
\hline Jenkins & $\mathrm{X}$ & & & & \\
\hline Kraft y furlong & & & & & $\mathrm{X}$ \\
\hline Lahera & & & & $\mathrm{X}$ & \\
\hline Mahone & & & & & $\mathrm{X}$ \\
\hline Meny y thoenig & & $\mathrm{X}$ & & & \\
\hline Plano & & & $\mathrm{X}$ & & \\
\hline Subirats y gomá & & & & & $\mathrm{X}$ \\
\hline Tamayo & & $\mathrm{X}$ & & & \\
\hline Laswell & & $\mathrm{X}$ & & $\mathrm{X}$ & \\
\hline Brum & & $\mathrm{X}$ & & & \\
\hline Manuel canto & $\mathrm{X}$ & & & $\mathrm{X}$ & $\mathrm{X}$ \\
\hline Lindblom & & & & & $\mathrm{X}$ \\
\hline Roth & $\mathrm{X}$ & & & & \\
\hline Medellin & $\mathrm{X}$ & & & & \\
\hline
\end{tabular}

Fuente: Elaboración propia

${ }^{22}$ CANTO, M. Introducción a las políticas públicas. In: Manuel Canto; O. Castro (Orgs). Participación Ciudadana y Políticas Públicas en el Municipio. México: MCD, 2002.

${ }^{23}$ KRAFT, Michael; FURLONG, Scott. Public Policy: Politics, Analysis and Alternatives. Washington DC: CQ Press, 2006.

${ }^{24}$ MAJONE, Giandomenico. Evidence, Argument \& Persuasion in the Policy process. New Haven: Yale University Press, 1989.

${ }^{25}$ SUBIRATS, J.; GOMÁ, R. Democratización, Dimensiones de Conflicto y Políticas Públicas en España. In: Ricard Gomá y Joan Subirats (Orgs). Políticas Públicas en España. Contenidos, Redes de Actores y Niveles de Gobierno. España: Ariel Ciencia Política, 1998. p. 13-36.

26 CANTO, M. Introducción a las políticas públicas. In: Manuel Canto; O. Castro (Orgs). Participación Ciudadana y Políticas Públicas en el Municipio. México: MCD, 2002.

${ }^{27}$ LINDBLOM, Charles. Usable knowledge: Social science and social problem solving. USA: Yale University Press, 1979. 
Ahora bien, analizando y problematizando cada uno de los elementos, si bien es cierto el elemento político es real, también es cierto que su nacimiento es o debiera ser anterior a esa discusión para la implementación; desde nuestro punto de vista, las políticas públicas deben nacer desde el momento mismo de la elección gubernamental, es más, antes, en la valoración que los ciudadanos hacen o debieran hacer de las diferentes propuestas de los que buscan conducir un país con su ideario o proyecto de nación. Por otro lado, los que apuntan a la acción gubernamental como la parte esencial de la política pública, si bien, resumen los dos momentos anteriores, se quedan cortos al no considerarlos tácitamente, ya que los elementos políticos son permanentes a lo largo del proceso. Peor aún, los que las hacen ver como una situación meramente administrativa, que en la práctica ciertamente se resuelven en eso, no es tan sencillo, cuestiones administrativas ya dijimos las tienen los propios gobiernos autoritarios. Por lo que el elemento o dimensión, la parte democrática de las políticas, resulta esencial, casi más que todas las demás, al ser una condición sine qua non de las políticas, para su carácter público, como se señaló al principio. Finalmente, llama la atención que se señale también como un conflicto entre valores, ideologías e intereses que pretenden regular a la sociedad, que ciertamente, difieren en tiempo, lugar y momento.

\section{LOS CICLOS Y PROCESOS DE LAS POLÍTICAS PÚBLICAS}

Respecto a lo cíclico y procesal de las políticas, se debe también, de algún modo a Harold Laswell ${ }^{28}$; se trata: de cómo se definen los problemas y las agendas, cómo se formulan, cómo se toman las decisiones y cómo se evalúan e implementan, proponiendo las siguientes fases o etapas: a) inteligencia: refiere a la importancia de la información y el conocimiento para la generación de modelos causales que permitan la planificación y la predicción; b) promoción: se vincula a la generación de alternativas de políticas; c) prescripción: se centra en el proceso de promulgación de las reglas; d) invocación: refiere a la caracterización provisional de conductas en función de las prescripciones establecidas en la etapa anterior; e) aplicación: se aboca al análisis del proceso de implementación de las reglas o decisiones; f) terminación: refiere al final de la política, una vez concluido el proceso de implementación, y g) evaluación:

\footnotetext{
${ }^{28}$ LASSWELL, H. La concepción emergente de las ciencias de políticas. In: Luis Aguilar V. El estudio de las políticas públicas. México: Porrúa, 1992. p. 79-117 apud JAIME, Fernando, et al. Introducción al análisis de políticas públicas. Argentina: Universidad Nacional Arturo Jauretche, 2013. p. 85-118. p. 86.
} 
se centra en el estudio de las consecuencias o efectos que la política genera y, que sirven para retroalimentar el proceso. ${ }^{29}$

Otros autores, señalan Jaime et $\mathrm{al}^{30}$, han desarrollado y redimensionado éstas consideraciones, ampliando el número de etapas o bien resumiéndolas; precisando en cada una de ellas la naturaleza de las preguntas a responder, la especificidad de los procesos políticos y técnicos involucrados, los requerimientos informacionales, los actores movilizados, el tipo de conflictividad que se genera, así como las aproximaciones metodológicas adecuadas, destacando las contribuciones de Jones ${ }^{31}$, Rose ${ }^{32}$, Brewer $^{33}$, Anderson $^{34}$, Jenkins ${ }^{35}$ o May y Wildavsky ${ }^{36}$.

La realizada por Jones ${ }^{37}$, señalan los autores, identifica cinco etapas: 1) la identificación del problema que reclama la atención del gobierno o sobre el que el gobierno desea/pretende intervenir; 2) la formulación de la política, que abarca la construcción de alternativas de políticas y la selección de un curso de acción; 3) la legitimación de la política o curso de acción elegido, esto comprende la argumentación, evidencias, símbolos y fundamentos que están detrás de la política pública elegida; 4) la aplicación, que refiere al proceso de administración o gestión de la política y que supone la conversión de los insumos puestos a disposición en productos o resultados consistentes con las metas establecidas en el estatuto de la política pública; y 5) la evaluación, que supone la medición de los resultados o consecuencias que la política produce sobre el contexto, los comportamientos de los actores, sus percepciones $\mathrm{y}$, en especial, sobre el problema atendido ${ }^{38}$.

La realizada por Anderson ${ }^{39}$, considera también cinco etapas: 1) la agenda: que refiere a los problemas que reciben la atención por parte del gobierno y supone explicar el proceso por el

29 JAIME, Fernando, et al. Introducción al análisis de políticas públicas. Argentina: Universidad Nacional Arturo Jauretche, 2013. p. 85-118. p. 86.

30 JAIME, Fernando, et al. Introducción al análisis de políticas públicas. Argentina: Universidad Nacional Arturo Jauretche, 2013. p. 85-118. p. 88.

31 JONES, Charles O. An Introduction of the Study of Public Policy. Belmont, California: Wadsworth Co., 1970.

32 ROSE, Richard. Comparing Public Policy: An Overview. In: European Journal of Political Research, v. 1, V. 1, 1973. p. 67-94.

${ }^{33}$ BREWER, Garry. The Policy Sciences Emerge: To Nurture and Structure a Discipline. In: Policy Sciences, v. 5 , v. 3. 1974. p. $139-244$.

${ }^{34}$ ANDERSON, James, Public Policy Making. New York: Rinehart y Winston, 1975.

35 JENKINS, William. Policy Analysis: A Political and Organizational Perspective. London: Martin Robertson, 1978.

${ }^{36}$ MAY, Judith; WILDAVSKY, Aaron. The Policy Cycle. Beverly Hills: Sage, 1978.

37 JONES, Charles O. An Introduction of the Study of Public Policy. Belmont, California: Wadsworth Co., 1970.

38 JAIME, Fernando, et al. Introducción al análisis de políticas públicas. Argentina: Universidad Nacional Arturo Jauretche, 2013. p. 85-118. p. 88.

${ }^{39}$ ANDERSON, James, Public Policy Making. New York: Rinehart y Winston, 1975. 
cual ciertos problemas son atendidos (no necesariamente resueltos) y otros no; 2 ) la formulación de alternativas: que comprende el desarrollo de propuestas de cursos de acción que sean aceptables, pertinentes y factibles, y exige dar cuenta de la racionalidad o no de ese proceso y del rol que juegan las ideas y el conocimiento experto; 3) la adopción de la decisión: incluye la elección y legitimación de un curso de acción y requiere explicar por qué se ha elegido o priorizado ese política en lugar de las otras alternativas; 4) la implementación: refiere al proceso de aplicación de la política y supone explicar los comportamientos administrativos que desencadena la política y la relación (causal) entre estos y los resultados de la política; y 5) la evaluación: refiere a los esfuerzos que los gobiernos realizan con el propósito de determinar la eficacia, eficiencia y efectividad de las políticas seleccionadas ${ }^{40}$.

Aguilar Villanueva ${ }^{41}$, amplía las clasificaciones. De acuerdo con su propuesta, señalan, el proceso de la política pública comprende siete etapas: La primera es la definición del problema. Aquí lo importante, es determinar cuál es el problema, cuáles son sus dimensiones o componentes y cuáles sus causas. La segunda es la formación de la agenda, que consiste en analizar qué factores contribuyen a que una situación se convierta en problema y ese problema en objeto de una acción gubernamental, y quienes son los actores que intervienen en el proceso. La siguiente etapa es la construcción de opciones, que consiste en analizar cuáles son las alternativas disponibles y viables para resolver el problema y qué riesgos, beneficios y costos acompaña a cada una de ellas. La cuarta etapa es la toma de decisión. Aquí el problema es determinar cuál de todas las alternativas disponibles constituye la mejor opción. La próxima etapa es la implementación de la política que consiste en analizar cuáles son las acciones conducentes para llevar a cabo exitosamente la decisión, para alcanzar los objetivos y metas que la política se propone. La sexta es la evaluación de la política. En esta etapa lo importante es decidir qué y cómo evaluar y para qué fines. Así llegamos a la última etapa, la de terminación o continuación de la política, que consiste en decidir a la luz de los insumos que brinda la evaluación si la política debe continuar, finalizar o revisarse ${ }^{42}$.

Ahora bien, propuestas más recientes resumen estos procesos en menos etapas o fases, que de algún modo concentran las anteriores, uno de ellos es Daniel Catalá, ver figura 1, quien a propósito señala que "diferentes autores definen varias etapas dentro del proceso o ciclo de las

\footnotetext{
40 JAIME, Fernando, et al. Introducción al análisis de políticas públicas. Argentina: Universidad Nacional Arturo Jauretche, 2013. p. 85-118. p. 88.

${ }^{41}$ AGUILAR Villanueva, L. Estudio Introductorio. In: VILLANUEVA, Luis Aguilar. La Hechura de las Políticas Públicas. México: Miguel Ángel Porrúa, 1996. p. 15-84.

42 JAIME, Fernando, et al. Introducción al análisis de políticas públicas. Argentina: Universidad Nacional Arturo Jauretche, 2013. p. 85-118. p. 88.
} 
políticas públicas, que se pueden concretar en cuatro etapas básicas (y) dentro de las cuales, en algún caso, se podría hablar de fases internas". ${ }^{43}$

Etapa de definición del problema, a su vez dividida en la fase de surgimiento e identificación del problema y la fase de incorporación del problema a la agenda política. En la fase de surgimiento, dice, una determinada situación produce una serie de efectos tales como una necesidad, colectiva, una carencia o una insatisfacción que se puede identificar o bien directamente o a través de ciertos elementos que la hacen visible. Una vez identificado el problema, la incorporación del mismo a la agenda política, dependerá del tratamiento político que se le dé, en función de la percepción que los decisores públicos tengan del mismo por su mayor o menor presencia en la media, el conocimiento científico que se tenga del mismo, la difusión de informaciones, el lobbying, la visibilidad de los afectados, etcétera.

Etapa de diseño de la política, dividida del mismo modo que la anterior en dos fases: la fase de formulación de alternativas y la fase de la decisión de la alternativa más adecuada. Una vez definido el problema, deben plantearse una serie de objetivos y metas relevantes a alcanzar, a partir de los cuales iniciar la búsqueda de alternativas (instrumentos y procesos), que debe pasar por examinar todas las soluciones posibles para el logro de las metas planteadas y analizar las consecuencias para cada alternativa de política con su probabilidad de ocurrencia; ahora bien, con las diferentes alternativas planteadas, el siguiente paso es compararlas teniendo siempre presentes los objetivos y metas previamente definidas y elegir la solución cuyos resultados proporcionan un mayor alcance de los mismos, mayores beneficios con costos iguales o menores costos con beneficios iguales.

Etapa de implementación de la política pública, aquí, se ponen en marcha y se ejecutan las alternativas o soluciones seleccionadas en la etapa anterior. Se lleva a cabo la secuencia programada de acciones definidas en busca de los objetivos planteados.

Etapa de evaluación de la política pública. Se constituye como parte fundamental del ciclo de las políticas, funciona como retroalimentación del proceso ya que la intervención pública no concluye con la evaluación de sus resultados, sino que ésta puede dar lugar a una nueva definición del problema que originó el ciclo. La evaluación pretende determinar los resultados y los efectos de una intervención pública ${ }^{44}$.

43 CATALÁ, Daniel. Las políticas públicas y su ciclo. Disponible en: https://totaleval.wordpress.com/2015/02/11/las-politicas-publicas-y-su-ciclo/. Accesado el: 15 ago. 2019. p. 02.

44 CATALÁ, Daniel. Las políticas públicas y su ciclo. Disponible en: https://totaleval.wordpress.com/2015/02/11/las-politicas-publicas-y-su-ciclo/. Accesado el: 15 ago. 2019 


\section{Figura 1 - EL CICLO DE LAS POLÍTICAS PÚBLICAS}

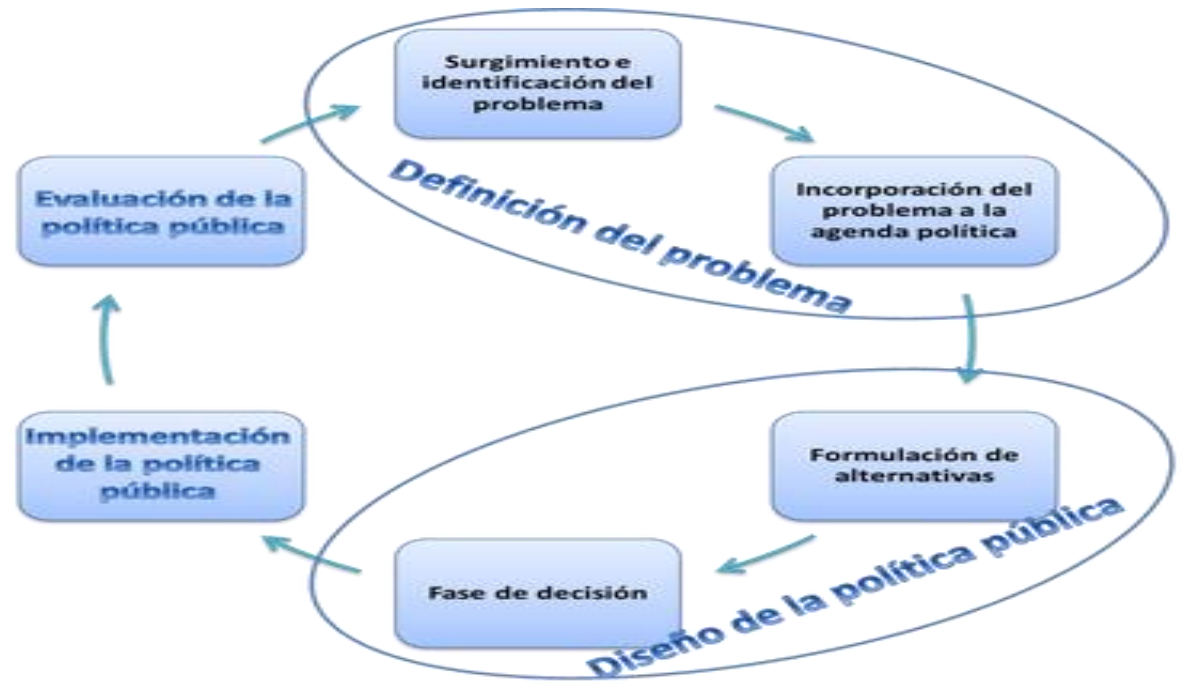

Fuente: Elaboración de Daniel Catalá. ${ }^{45}$

En el mismo tenor, Carlos Aguilar Astorga y Marco Antonio Lima Facio ${ }^{46}$ en: ¿Qué son y para qué sirven las Políticas Públicas?, proponen un modelo basado en diferentes autores, reconociendo también cuatro etapas: Gestación Formulación, Implementación y Evaluación. Su descripción gráfica, señalan, permite ver una "fotografía" de este complejo proceso de decisiones. Se opta, por desarrollar el modelo de ciclo (fases o etapas), por considerarlo explicativo, pero de ninguna manera, señalan, deben entenderse como algo estático y de un sólo orden. En la realidad, las fases de la política tienden a desdibujarse, dicen, superponerse y entremezclarse, pensar en un modelo infalible y un concepto único, sería algo cercano al fanatismo. las definiciones de cada una de las partes sería la siguiente:

Gestación: La detección de un problema público, dicen, tiene que ver con uno privado (o varios) de trascendencia pública, esto es, un problema público implica problemas individuales pero no aislados, sino que esta manifestación de problemas individuales concentrados en un problema público es de implicación gubernamental $y$, dado que el gobierno cuenta con recursos escasos (no solo monetarios sino temporales, de personal, etcétera), elegir qué problemas públicos van a ser de consideración gubernamental implica necesariamente un conflicto que

45 CATALÁ, Daniel. Las políticas públicas y su ciclo. Disponible en: https://totaleval.wordpress.com/2015/02/11/las-politicas-publicas-y-su-ciclo/. Accesado el: 15 ago. 2019 ${ }^{46}$ AGUILAR Astorga, Carlos; LIMA F., Marco Antonio. ¿Qué son y para qué sirven las Políticas Públicas?, en Contribuciones a las Ciencias Sociales, septiembre $2009 . \quad$ Disponible en: www.eumed.net/rev/cccss/05/aalf.htm. Accesado el: 10 jul. 2018. 
dejará a unos fuera. En esta fase, el gobierno tiene que responder a la pregunta ¿qué es más importante entre $\mathrm{x}, \mathrm{y}, \mathrm{z}$ ?, ¿es más importante, generar empleos, ceder a los empresarios, ayudar a los indígenas, resolver el problema de escases de agua, ampliar la base gravable, pavimentar las calles?, ¿resolver lo inmediato o lo urgente?

Formulación: A esta elección del gobierno, se le llama agenda de gobierno y puede entenderse como el elemento que une la gestación con la formulación de la política. En este momento se da la discusión sobre la alternativa que se adoptará para corregir el problema, lo cual está acotado por las capacidades técnicas, financieras, temporales y humanas, de los que discutan el problema. Citando a Aguilar Villanueva, dicen: "Se puede llamar propiamente formación de la agenda gubernativa al proceso mediante el cual las demandas de varios grupos de la población y el gobierno se transforman en asuntos que compiten por alcanzar la atención seria de las autoridades públicas” ${ }^{47}$. Por lo regular, es donde los diagnósticos tienen una fuerza determinante, pues de acuerdo a estos, la política tendrá forma. 0 , dicho de otro modo, un mal diagnóstico llevará a una mala implementación. También es claro que quien presente mejores diagnósticos es quien acapare las agendas de gobierno, pues es más fácil formular una política si el diagnóstico funciona como elemento disparador a una posible solución.

Implementación: La implementación es la puesta en práctica del diseño que se elige y se construye para abordar el problema. Cabe mencionarse que, en los países anglosajones, señalan los autores, se desarrolló desde los setentas una amplia bibliografía, pues se dieron cuenta que un diseño bien hecho no necesariamente lleva a una puesta en práctica sin problemas. La pregunta clave es: ¿Por qué falla la implementación si el diseño es eficiente?, como se señaló con anterioridad, la variabilidad en la política, así como en la mayoría de las ciencias sociales es irremediable, al tener escenarios, actores, intereses, cambiantes, la implementación se desajusta del diseño. Incluso es 'el talón de Aquiles de la política', precisamente por la dinámica implícita. Lo que ha desarrollado que los indicadores (en este caso de implementación) tengan una relevancia significativa. Regularmente, aquellos actores que no pudieron influir en el proceso de decisión (formulación), tratarán de recuperar ese poder en la fase de implementación, haciéndola más compleja.

Evaluación: Finalmente, la evaluación consiste dicen, en la realización de una investigación, de tendencia interdisciplinaria, cuyo objetivo es conocer, explicar y valorar, mediante la aplicación de un método sistemático, el nivel de logros alcanzado (resultados e impactos) por las políticas y programas públicos, así como aportar elementos al proceso de toma

${ }^{47}$ AGUILAR Villanueva, L. Antologías de Política Pública. México: Porrúa, 1993. p. 25. 
de decisiones para mejorar los efectos de la actividad evaluada. Al tiempo que señalar, que es la parte menos desarrollada de las políticas públicas, aunque existe una amplia gama de estas, apuntan.

Si observamos, no hay un común denominador en todos ellos, pero ciertamente, como señalan Aguilar y $\operatorname{Lima}^{48}$, se pueden caracterizar y resumir en cuatro grandes etapas: Gestación, Formulación, Implementación y Evaluación, con la cual coincidimos, pero que al mismo tiempo se difiere, concretamente en la parte de la evaluación, ya que para nosotros, la evaluación debe ser permanente y, particularmente durante el proceso de implementación.

\section{EL CARÁCTER PÚBLICO DE LAS POLÍtICAS PÚBLICAS Y LA PARTICIPACIÓN CIUDADANA}

Ahora bien, un elemento importante a considerar es el carácter público de las políticas. Si bien, las diferencias entre público y lo privado han dependido del momento histórico, resulta curioso y hasta paradójico, señalan Aguilar y Lima $^{49}$ que lo público es asociado con lo gubernamental, como si los gobiernos tuvieran el monopolio de lo público. La política pública, dicen, es un pleonasmo, pues la política desde los griegos era una actividad que se realizaba en la polis y no podía ejercerse sino en público (la familia era un espacio pre político y por ende privado, era el oikos). Público y política para los griegos era algo similar porque no había concepción de lo individual, la política era pública y lo público era político. Con Maquiavelo, señalan, es que comenzó a manifestarse un realismo de la política distinto al mundo helénico, se pone de manifiesto que la política está en manos de algunas élites y que la cosa pública, o la res publica, no pertenece a todo (el) público. Desde ese punto de vista, dicen, una de las principales aportaciones de las políticas públicas es precisamente rescatar el carácter público de las políticas; la intervención de actores diferentes al gubernamental en las políticas (sindicatos, organizaciones de la sociedad civil, empresas, iglesias, asambleas vecinales, etcétera). Este ámbito público es el campo en el que los ciudadanos individuales, por sí mismos o por los

\footnotetext{
${ }^{48}$ AGUILAR Astorga, Carlos; LIMA F., Marco Antonio. ¿Qué son y para qué sirven las Políticas Públicas?, en Contribuciones a las Ciencias Sociales, septiembre 2009. Disponible en: www.eumed.net/rev/cccss/05/aalf.htm. Accesado el: 10 jul. 2018.

${ }^{49}$ AGUILAR Astorga, Carlos; LIMA F., Marco Antonio. ¿Qué son y para qué sirven las Políticas Públicas?, en Contribuciones a las Ciencias Sociales, septiembre 2009. Disponible en: www.eumed.net/rev/cccss/05/aalf.htm. Accesado el: 10 jul. 2018. p. 3-4.
} 
voceros de sus organizaciones, hacen política y hacen las políticas, hasta aquí la referencia a Aguilar y Lima. $^{50}$

Ahora bien, desde nuestro punto de vista, no está mal que lo público se refiera al gobierno, pero no es suficiente; ciertamente, hace falta la otra parte, lo público visto desde quienes intervienen (o debieran intervenir) en ellas, pero consideradas incluso desde más allá. La intervención de lo público, o del público, no puede ser sólo en su formulación e implementación, sino desde el momento mismo de la elección o "selección" del propio gobierno; de los candidatos que se consideraron triunfadores y, por cierto, en la evaluación misma de las políticas. La otra característica o condicionante de lo público, señalamos, sería su destino, hacia a quien se dirigen o debieran ser dirigidas las políticas públicas; que dicho sea de paso, puede haber algunas que estén dirigidas al propio aparato gubernamental y hasta específicamente a las esferas privadas, sin embargo, con un propósito siempre público o de beneficio público.

La condicionante ciudadana en la elaboración y formulación de las políticas públicas debe considerar su participación libre y democrática, sino, no adquieren ese carácter, ésta debe aparecer desde el momento de la elección o selección de los gobernantes al apoyar, con su voto, tal o cual gobierno o proyecto de gobierno en desestimación de otros. Estamos ciertos, que a mayor solidez y madurez de las democracias, mayor calidad de las políticas públicas, es decir, la participación ciudadana en las políticas públicas de las democracias no está aparte de ella, sino como parte de ella. Pero esta participación, debe ser permanente, no sólo en su Elaboración e Implementación, sino como señalamos, desde la Gestación y hasta la propia Evaluación. A mayor democracia, habrá mayor participación, señalan Aguilar y Lima Facio ${ }^{51}$. Vincular participación ciudadana en las fases de las políticas mejoraría el desempeño de los representantes políticos y daría mejores soluciones a los problemas públicos. ¿Qué personas deben participar en qué fases? Es un tema muy polémico, señalan, que implica un análisis en cada fase y en cada nivel. Ciertamente, a lo mejor la democracia no está aún madura para estas pretensiones, pero eso no es culpa de las políticas, en todo caso, de la democracia.

\footnotetext{
${ }^{50}$ AGUILAR Astorga, Carlos; LIMA F., Marco Antonio. ¿Qué son y para qué sirven las Políticas Públicas?, en Contribuciones a las Ciencias Sociales, septiembre 2009. Disponible en: www.eumed.net/rev/cccss/05/aalf.htm. Accesado el: 10 jul. 2018.

${ }^{51}$ AGUILAR Astorga, Carlos; LIMA F., Marco Antonio. ¿Qué son y para qué sirven las Políticas Públicas?, en Contribuciones a las Ciencias Sociales, septiembre 2009. Disponible en: www.eumed.net/rev/cccss/05/aalf.htm. Accesado el: 10 jul. 2018. p. 11.
} 


\section{SOBRE LOS PROBLEMAS DE LAS POLÍTICAS PÚBLICAS}

Es decir, pues, los problemas para las políticas públicas desde nuestro punto de vista, se presentan desde el momento mismo de su gestación u origen, que debiera ser ésta reconocida desde la propia elección de los gobernantes, por ciudadanos capacitados y libres. En la programación, que debiera ser considerada, tanto en la formulación y la implementación, como una reprogramación y represupuestación como un conector precisamente entre ambas y, la evaluación, ciertamente ex ante-ex post, pero particularmente “durante" el proceso de implementación.

Hay otros problemas más. Uno que se aprecia muy recurrente está en la definición del problema; si bien es cierto, la mayoría de los procesos y exponentes lo definen y contemplan, en la práctica, el problema del problema es su cabal identificación, ya que la mayoría de las veces es muy común relacionarlo con los efectos que éste ocasiona y no con el verdadero problema, es decir las causas que lo originan, qué sería en todo caso el verdadero problema, ahora sí que el problema del problema, es su problema, aunque parezca un juego de palabras. $\mathrm{Y}$ esto es importante, porque estamos ciertos que desde ese momento, la política pública definida e implementada, ya no será exitosa ${ }^{52}$.

Ahora bien, pero considerando que haya sido debidamente identificado, lo que sigue como se señaló, es formular las posibles alternativas de solución y evaluarlas; pero esta formulación no es simplemente "proponer ideas" de solución, sino alternativas debidamente medidas, evaluadas y cuantificadas, ciertamente ex ante, para conocer sus posibilidades de éxito y seleccionar la que se considere de mayor eficiencia, para ello, no hay una fórmula unívoca, pero se supone, que si uno tiene bien detectado el problema y, dimensionado, se podrán, considerando los resultados deseados, evaluar con base en ello las distintas alternativas. Es decir, qué es lo que me gustaría lograr y cuál de ellas me ofrece la mejor opción para lograrlo, por lo que la evaluación ex-ante de la alternativa, no considera o debe considerar solamente la solución, sino particularmente la medida de esa solución; en todos los aspectos, técnicos, económicos y financieros, programados. Pero también, políticos, económicos, sociales, normativos, culturales y ambientales, por lo que la idea que se está proponiendo es un análisis

\footnotetext{
52 AGUILAR Astorga, Carlos; LIMA F., Marco Antonio. ¿Qué son y para qué sirven las Políticas Públicas?, en Contribuciones a las Ciencias Sociales, septiembre 2009. Disponible en: www.eumed.net/rev/cccss/05/aalf.htm. Accesado el: 10 jul. 2018.
} 
FODA (Fortalezas, Oportunidades, Debilidades y Amenazas), incluso antes de la programación. No siempre la alternativa más deseada, es la más posible o eficiente.

Supongamos ahora que, efectivamente logramos decidir bajo estos principios la mejor opción ¿qué sigue?: su implementación, hay que considerar y reconsiderar los tiempos, responsables y formas de medición, reprogramación y represupuestación, que vienen o debieran venir como señalamos programados desde la formulación, que posibilite, llevar un control de su implementación. Pero ésta implementación, tampoco es sólo llevarla a cabo como algo inercial o técnico, sino como ya se dijo, evaluando también su desarrollo permanentemente, y es ahí donde estriba el otro problema de su eficiencia; la mayoría de los autores que consideran la evaluación (ex-post), se refieren a sus resultados finales, lo que desde nuestro punto de vista es un serio error; el no dar el acompañamiento a las políticas públicas durante su desarrollo, para controlar, adecuar, ajustar, modificar o incluso parar su proceso, es uno de los principales problemas de las políticas públicas.

Recordemos, que nosotros recomendamos desde la propia formulación la implantación de indicadores programados que medirán ciertamente lo deseado al final del proceso, pero no tener subindicadores o submetas que "direccionen" ese final y ese logro, sería un grave error y menos no darles el seguimiento adecuado; las políticas públicas deben considerar sí indicadores finales, pero sobre todo, subindicadores de medición durante el proceso o submetas, de corto y mediano plazo, concordantes con las metas e indicadores finales programados, sino, el proceso se queda "suelto" y lo que es peor, esperando sólo el resultado final, sin la posibilidad ya de su reversión, ajuste o cambio, o a precios muy altos.

\section{LA PROGRAMACIÓN DE LAS POLÍTICAS PÚBLICAS}

Por eso es para nosotros muy importante la programación, porque en ella estriba la direccionalidad de la política(s). No obstante, sobre la programación de las políticas, no hay mucho que decir, como señalamos, los autores las consideran implícitas, asumimos, en la formulación, pero la pregunta es si ésta se llevó a cabo cabalmente, y no nos referimos a las obras o acciones, solamente, sino a la política en sí, independientemente de las obras y acciones que se van a desarrollar para llevarla a cabo. Es importante, también por lo mismo, hacer la presupuestación y la valoración de las mismas, con el análisis FODA recomendado, primero incluso que ambos. $\mathrm{Y}$, particularmente, una reprogramación y represupuestación, en la fase ya de implementación. Muchas veces las políticas o decisiones tomadas tardan mucho en ser 
levadas a cabo o implementadas y, las obras o acciones que revisten deben reconsiderarse, toda vez que los tiempos y circunstancias se mueven. Entre más pronto se implemente una política formulada es mejor. Acarreará menos costos y menos riesgos de contratiempo.

Es decir, desde nuestro punto de vista, la programación es esencial, porque recoge los tiempos, indicadores, responsables y presupuestos, de las políticas públicas a implementar, pero por lo mismo, se deben reprogramar, no debe de morir ahí, por el contrario, es la conexión con el otro "momento" de las políticas públicas, pasar del escritorio a la práctica, donde no solo no debe desaparecer, sino precisamente se efectiviza, tal cual, sino, la política pública no está, ni estará bien desarrollada o implementada. Es decir, la programación y presupuestación, deben sucederse desde el momento de la formulación y continuar en el proceso de implementación como una reprogramación y represupuestación, si se ocupara.

\section{LA EVALUACIÓN DE LAS POLÍTICAS PÚBLICAS}

La evaluación de políticas públicas no es un fenómeno nuevo, pero lo mismo que en su momento la implementación, no configuraba parte importante del proceso en los primeros años; pero al dar un sentido cíclico a éstas, y sobre todo integral, como un proceso, es que revistió vital importancia. En la actualidad, es parte esencial de todo el proceso y, todos los autores la consideran de una u otra manera como una de las etapas. Sin embargo, la parte novedosa de nuestra intervención es sugerirla y considerarla en una parte que no ha sido directamente incursionada por los investigadores y que, a nuestro parecer, ayudaría a eficientar indiscutiblemente el proceso: durante la etapa de su implementación.

La evaluación, "es una actividad que procura abrir juicios con respecto a los productos, resultados e impactos de las políticas públicas", señalan Jaime, et $\mathrm{al}^{53}$. La búsqueda de técnicas y metodologías dirigidas a introducir mejor fundamentación a las argumentaciones en torno a las políticas públicas y a la valoración de sus resultados y efectos, señalan, se ha convertido en las últimas décadas en una de las preocupaciones centrales del análisis de políticas, apuntando que sus contribuciones se refieren a diversos planos:

La Fundamentación sistemática de juicios sobre la política y su gestión: que estima de manera rigurosa y a través de evidencias el logro de las metas requiere la identificación y medición de productos y resultados y posibilita la medición de la eficiencia, la eficacia y la

53 JAIME, Fernando, et al. Introducción al análisis de políticas públicas. Argentina: Universidad Nacional Arturo Jauretche, 2013. p. 85-118. p. 112. 
efectividad. Identifica problemas de diseño de las políticas y de los procesos de implementación. ${ }^{54}$

La Transparencia y control social: a través de éstas, se reafirma lo "público" como la esfera de interés común, abre la posibilidad del debatir implicancias y consecuencias de ideas alternativas y es expresión de la subordinación de la acción del estado a la sociedad en su carácter de mandatario y de gestor del bien común. ${ }^{55}$

El Perfeccionamiento constante: como esfuerzo sistemático brinda elementos para la revisión de las políticas y para encarar acciones de fortalecimiento y desarrollo de la gestión pública. ${ }^{56}$

El Aprendizaje y generación de conocimiento: la evaluación, permite incorporar las lecciones de la experiencia, pone a prueba las hipótesis que sostienen las políticas, ayuda a comprender mejor los problemas y contribuye a alcanzar una mayor apreciación del potencial de medios e instrumentos y de la viabilidad de estrategias y cursos de acción. ${ }^{57}$

Definimos, a la evaluación como una práctica integral de construcción, análisis y comunicación de información útil para mejorar aspectos de la definición e implementación de las políticas públicas, un proceso de aprendizaje que incluye la reflexión crítica sobre los aciertos y errores cometidos y la consecuente modificación de los cursos de acción. ${ }^{58}$

Existe cierto nivel de consenso, apuntan, en la comunidad de académicos e investigadores acerca de que la evaluación de políticas públicas resulta una estrategia central a la integración de las acciones de gobierno y la calidad de las intervenciones de la administración pública en las realidades sociales. Una de las principales ideas a tener en cuenta frente al desafío de pensar, describir o proponer sistemas de evaluación es la contemplación de un modelo de evaluación integral, construido a partir de la complejidad que la acción estatal presenta, la urgencia de mejorar la calidad de las políticas y la necesaria articulación de la

\footnotetext{
${ }^{54}$ JAIME, Fernando, et al. Introducción al análisis de políticas públicas. Argentina: Universidad Nacional Arturo Jauretche, 2013. p. 85-118.

55 JAIME, Fernando, et al. Introducción al análisis de políticas públicas. Argentina: Universidad Nacional Arturo Jauretche, 2013. p. 85-118.

56 JAIME, Fernando, et al. Introducción al análisis de políticas públicas. Argentina: Universidad Nacional Arturo Jauretche, 2013. p. 85-118.

57 JAIME, Fernando, et al. Introducción al análisis de políticas públicas. Argentina: Universidad Nacional Arturo Jauretche, 2013. p. 85-118.

58 JAIME, Fernando, et al. Introducción al análisis de políticas públicas. Argentina: Universidad Nacional Arturo Jauretche, 2013. p. 85-118. p. 112.
} 
esfera política y la esfera técnica que conviven y habitualmente confrontan en la administración.

Las primeras evaluaciones estuvieron fundadas sobre el paradigma de la investigación experimental. Sus complejidades y limitaciones fueron superadas por estrategias de indagación atentas a la diversidad de apreciaciones de diferentes actores, a las ambigüedades de la situación de partida y, al carácter múltiple de los resultados e impactos. En las últimas décadas, no obstante, señalan, se han venido desplegando esfuerzos para incorporar la evaluación como práctica sistemática para el diseño, el seguimiento y la gestión de políticas y programas. En la actualidad, los países con mayores capacidades políticas y técnicas cuentan con ámbitos institucionalizados para esa evaluación.

Bajo estas premisas, es que nuestra propuesta encuentra un resquicio $y$, apunta a proponer un nuevo modelo para la creación y el desarrollo de las políticas públicas, donde la evaluación, principalmente durante el proceso de implementación, juega un papel trascendental.

\section{NUESTRA PROPUESTA}

La primera intención que se persigue es advertir ciertamente que las políticas públicas son un proceso, no sé si un ciclo, es decir si debiera éste ser circular o con terminación, más adelante los discutiremos, pero si un proceso. Donde hay, o debiera haber, ciertamente cuatro etapas interconectadas: Gestación, Formulación, Implementación y Evaluación, pero conectadas la Formulación e Implementación, con la programación, en ese orden, mediadas por el presupuesto, no concordamos que puedan aparecer unas primero y otras después, pero en lo que sí coincidimos y diferenciamos, es en ello, que la programación debe existir desde antes de la implementación y que, el proceso de evaluación debe ser permanente y extenderse a las otras etapas de la política, particularmente a la formulación e implementación, pero incluso a la propia evaluación, porque otro elemento que proponemos es la participación democrática, libre y consciente de la población en todas las etapas de la política pública, que dicho sea de paso y como se ha insistido, comienza en el mismo momento de la gestación, con su voto; proponemos además una etapa de Aprobación y Legitimación, que pudiera ser parte de la Formulación (ver figura 3 al final), no debería implementarse una política que no se apruebe y legitime antes, pero por su importancia y los actores que participan o debieran participar, se ponen por separado, incluso como un proceso en sí mismo, además, la Evaluación y Seguimiento o 
Evaluación Durante, que es el corazón de nuestro trabajo. La propuesta completa sería la siguiente (cuadro 2, figura 2):

Cuadro 2 - MOMENTOS, ETAPAS Y ACTORES DE LA POLÍTICA PÚBLICA

\begin{tabular}{|c|c|c|c|c|c|c|}
\hline MOME & \multicolumn{2}{|c|}{ ELABORACIÓN DE LA POLITICA } & APROBACIÓN & \multicolumn{3}{|c|}{ IMPLEMENTACIÓN } \\
\hline $\begin{array}{l}\text { ETAPAS/ } \\
\text { ACTORES }\end{array}$ & $\begin{array}{c}\text { GESTACIÓN Y/Ö } \\
\text { NACIMIENTO } \\
\text { (APARAICIÓN, } \\
\text { CONOCIMIENTO O } \\
\text { PRESENTACIÓN DEL } \\
\text { PROBLEMA O } \\
\text { SITUACIÓN Y SU } \\
\text { INCLUSIÓN O NÓ EN LA } \\
\text { AGENDA) }\end{array}$ & $\begin{array}{c}\text { VALORACIÓN Y } \\
\text { FORMULACIÓN } \\
\text { (DEL } \\
\text { PROGRAMA, } \\
\text { PROYECTO O } \\
\text { ACCIÓN } \\
\text { ESPECÍFICA A } \\
\text { SEGUIR O NÓ) }\end{array}$ & $\begin{array}{c}\text { APROBACIÓN } \\
\text { Y } \\
\text { LEGITIMACIÓN }\end{array}$ & IMPLEMENTACIÓN & $\begin{array}{c}\text { EVALUACIÓN } \\
\text { Y } \\
\text { SEGUIMIENTO }\end{array}$ & $\begin{array}{l}\text { EVALUACIÓN } \\
\text { FINAL }\end{array}$ \\
\hline $\begin{array}{l}\text { ACTORES } \\
\text { POLIITICOS } \\
\text { (CANDIDATOS, } \\
\text { PARTIDOS, } \\
\text { ORGANIZACIONES } \\
\text { POLIITICAS) }\end{array}$ & $\begin{array}{l}\text { Propuestas de campaña } \\
\text { o propuestas durante } \\
\text { gobierno. }\end{array}$ & $\begin{array}{l}\text { Participación } \\
\text { directa o } \\
\text { indirecta, según } \\
\text { lo determinen. }\end{array}$ & $\begin{array}{l}\text { Gobernantes, } \\
\text { partidos y } \\
\text { líderes } \\
\text { políticos. }\end{array}$ & $\begin{array}{l}\text { Participación } \\
\text { directa o } \\
\text { indirecta, según } \\
\text { se determine. }\end{array}$ & $\begin{array}{l}\text { Evaluación } \\
\text { permanente } \\
\text { durante el } \\
\text { proceso de } \\
\text { implementaci } \\
\text { ón. }\end{array}$ & $\begin{array}{l}\text { Evaluación } \\
\text { final de los } \\
\text { resultados } \\
\text { obtenidos y/o } \\
\text { recalendarizac } \\
\text { ión. }\end{array}$ \\
\hline $\begin{array}{l}\text { CIUDADANOS Y } \\
\text { SOCIEDAD EN } \\
\text { GENERAL } \\
\text { (EMPRESAS, } \\
\text { ONG'S, } \\
\text { UNIVERSIDADES, } \\
\text { IGLESIAS, } \\
\text { SINDICATOS } \\
\text { ETCÉTERA) }\end{array}$ & $\begin{array}{l}\text { Elección y selección con } \\
\text { su voto de los } \\
\text { gobernantes. } \\
\text { Participación en planes } \\
\text { gubernamentales. } \\
\text { Demandas o inputs. }\end{array}$ & $\begin{array}{l}\text { Participación } \\
\text { directa o } \\
\text { indirecta, según } \\
\text { se determine. }\end{array}$ & $\begin{array}{l}\text { Participación } \\
\text { organizada } \\
\text { directa para } \\
\text { presionar su } \\
\text { aprobación o } \\
\text { desaprobación } \\
\text { - }\end{array}$ & $\begin{array}{l}\text { Participación } \\
\text { directa o } \\
\text { indirecta, según } \\
\text { se determine. }\end{array}$ & $\begin{array}{l}\text { Evaluación } \\
\text { permanente } \\
\text { durante el } \\
\text { proceso de } \\
\text { implementaci } \\
\text { ón. }\end{array}$ & $\begin{array}{l}\text { Evaluación } \\
\text { final de los } \\
\text { resultados } \\
\text { obtenidos y/o } \\
\text { recalendarizac } \\
\text { ión. }\end{array}$ \\
\hline GOBIERNO & $\begin{array}{l}\text { Conocimiento y } \\
\text { detección de la } \\
\text { propuesta o situación y } \\
\text { decisión de si se incluye } \\
\text { o no en la agenda. }\end{array}$ & $\begin{array}{l}\text { Definición } \\
\text { correcta del } \\
\text { problema o } \\
\text { situación } \\
\text { (causas } \\
\text { principales). } \\
\text { Elaboración y/o } \\
\text { evaluación } \\
\text { correcta de las } \\
\text { alternativas con } \\
\text { solución } \\
\text { operativa, } \\
\text { técnica, política } \\
\text { y financiera. } \\
\text { Valoración de } \\
\text { tiempos, } \\
\text { responsables } \\
\text { financiamiento } \\
\text { y metas } \\
\text { escalonadas de } \\
\text { cumplimiento. } \\
\text { Programación. } \\
\text { Selección de la } \\
\text { alternativa } \\
\text { apropiada. }\end{array}$ & $\begin{array}{l}\text { Presentación y } \\
\text { justificación } \\
\text { de la Política } \\
\text { Pública. }\end{array}$ & $\begin{array}{l}\text { Participación } \\
\text { directa. } \\
\text { Re-programación } \\
\text { o ajuste de la } \\
\text { programación y } \\
\text { presupuestación. } \\
\text { Ejecución. }\end{array}$ & $\begin{array}{l}\text { Evaluación } \\
\text { permanente } \\
\text { durante el } \\
\text { proceso de } \\
\text { implementaci } \\
\text { ón. }\end{array}$ & $\begin{array}{l}\text { Evaluación } \\
\text { final de los } \\
\text { resultados. } \\
\text { Finalización de } \\
\text { la política, } \\
\text { adecuación o } \\
\text { continuidad. }\end{array}$ \\
\hline
\end{tabular}

Fuente: Elaboración propia. 
ISSN 1981-3694

(DOI): 10.5902/1981369447071

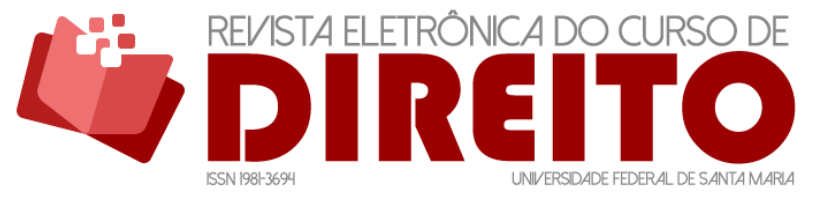

AVALIAÇÃO DURANTE: O CORAÇÃO DAS POLÍTICAS PÚBLICAS PARA UM MODELO GERAL DE CRIAÇÃO DE POLITICAS PÚBLICAS

\section{Figura 2 - ETAPAS Y FASES DE LAS POLÍTICAS PÚBLICAS}

\section{I) PROCESO DE ELABORACIÓN}

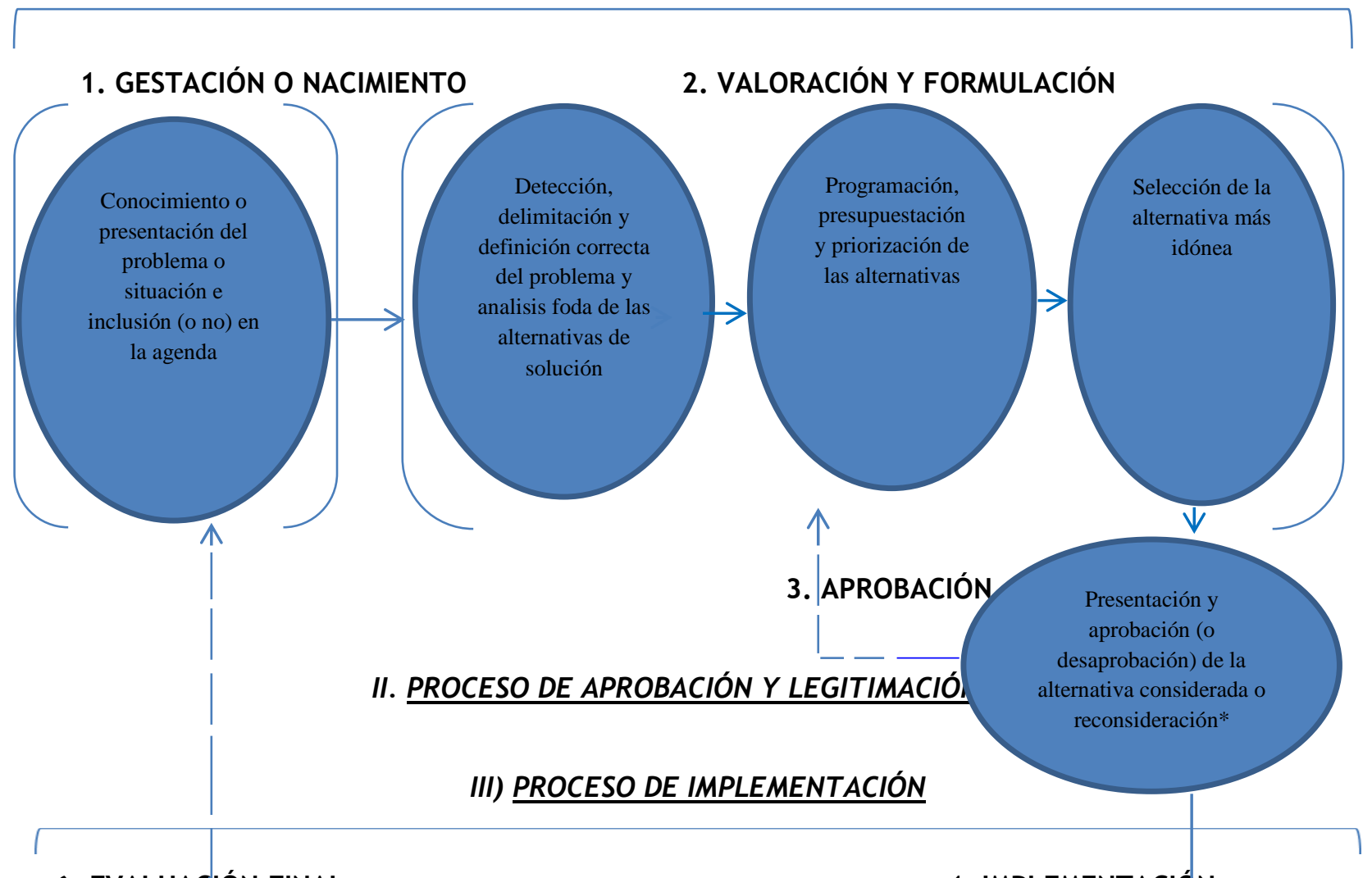

6. EVALUACIÓN FINAL

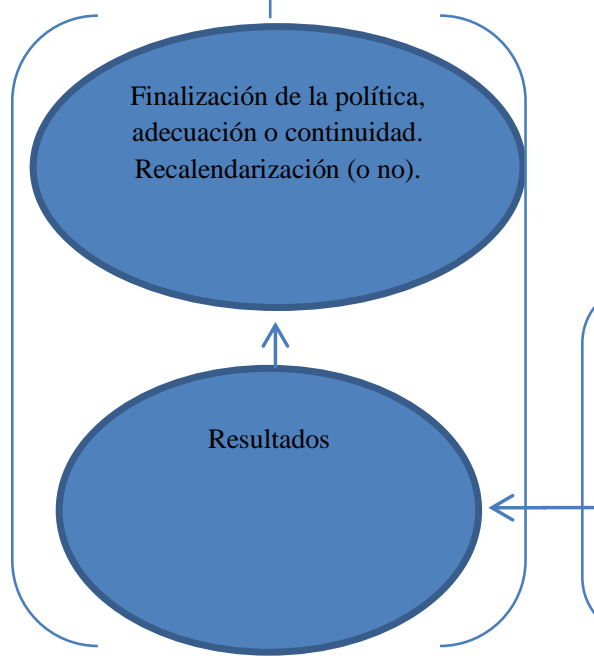

Fuente: Elaboración propia

* Se puede considerar la etapa de aprobación y legitimación en la Formulación ver figura 3 al final anexa. 


\subsection{Definiciones}

NACIMIENTO O GESTACIÓN. Vamos a usar la palabra gestación o nacimiento, a propósito, porque en nuestro caso convenimos la gestación o nacimiento de la política desde el momento mismo de la elección de los candidatos y las propuestas de éstos sobre los problemas y políticas (soluciones) que consideran más importantes a instrumentar de llegar a ser electos, por lo que se supone que, si es así, los electores estarán eligiendo desde el primer momento las políticas públicas que les interesan, con su voto. De no ser así, y no, una política ideal, como comentamos, aún así se iniciará la política con la gestación y el nacimiento a partir de que los gobernantes, o una fuerza social o pública ${ }^{59}$ las consideran, los problemas, y los colocan en la agenda, para su posible atención. Participan entonces, de algún modo, las fuerzas sociales, los ciudadanos libres, sindicatos, organizaciones, universidades, iglesias, etcétera, con sus demandas, en dos momentos, en la elección o selección misma de los gobernantes en turno y, durante el o los procesos de gobierno, por otro, los actores políticos, partidos y organizaciones políticas, y el propio gobierno, en dos momentos también, con sus propuestas de campaña y/o sus decisiones ya como gobernantes.

NACIMIENTO DEL PROBLEMA E INCLUSIÓN (O NO) EN LA AGENDA. Se refiere al "nacimiento" o manifestación del problema y su inclusión (o no) en la agenda, exhibido o manifestado por los ciudadanos desde el momento mismo incluso de la elección o selección de los gobernantes o, durante los gobiernos, o bien por la decisión de éstos durante su mandato, de considerarlos o no en la agenda, por los ciudadanos, actores políticos o grupos de presión y, por los gobernantes, con sus propuestas como candidatos, o ya como gobernantes.

VALORACIÓN Y FORMULACIÓN. Se trata de detectar, definir y decidir qué hacer con el problema o situación "aceptado", considerando las alternativas susceptibles de solución; muchas veces confundido o atendido como los efectos y no las causas, cual debiera ser, nacido, como se dijo, incluso desde el momento mismo de la elección al "manifestarse" el ciudadano con su voto. La valoración-evaluación de qué hacer $y$, formulación, la hace particularmente el gobernante en turno, con el apoyo de expertos, aunque puede incluir también opiniones del público y otros actores políticos. Comprende básicamente tres fases: la valoración-evaluación de las alternativas, selección y priorización de las más viables y la selección final. En esta etapa

${ }^{59}$ AGUILAR Villanueva, L. Estudio Introductorio. In: VILLANUEVA, Luis Aguilar. La Hechura de las Políticas Públicas. México: Miguel Ángel Porrúa, 1996. p. 15-84. 
debe ser insustituible un análisis FODA (Fortalezas, Oportunidades, Debilidades y Amenazas), sobre todo en la parte inicial de valoración-evaluación de las alternativas, así como la programación y presupuestación. Participan o pudieran participar todos, ciudadanos y actores políticos, de hecho, muchas de las veces y en muchas democracias se presentan demandas formuladas o iniciativas (legales) de políticas públicas por parte de los ciudadanos, pero ciertamente será responsabilidad del gobierno su elaboración y aceptación final.

ANÁLISIS FODA DE LAS ALTERNATIVAS DE SOLUCIÓN. Una vez detectado y definido el problema o situación que se desea atender, hay que valorar y evaluar las opciones para su solución, primero mediante un análisis FODA (Fortalezas, Oportunidades, Debilidades y Amenazas), que nos permitirá en un primer momento y cernido, filtrar las más acordes y posibles, legal, social, económicamente, ambiental y culturalmente, entre otros aspectos, antes del análisis técnico y presupuestal.

PROGRAMACIÓN Y EVALUACIÓN Y PRIORIZACIÓN DE LAS ALTERNATIVAS. De las alternativas susceptibles de realización por el análisis FODA, se pasa entonces a valorarlas técnicamente, en su programación y presupuestación, estableciendo metas, tiempos, responsables y periodos de ejecución, con sub metas medibles y cuantificables de corto y mediano plazo en razón de los resultados o metas finales deseables, medibles y cuantificables; se tienen que y deben valorar, todas las alternativas que se mantienen sugiriéndose una priorización de mayor a menor, considerando la más deseable o eficiente, pero sin desechar todas las demás que resulten viables.

SELECCIÓN DE LA ALTERNATIVA MÁS EFICIENTE. Con base a ello, se selecciona la alternativa que se considere más apropiada o eficiente, pero manteniendo o conservando las demás opciones, priorizadas, por orden de importancia y eficiencia.

APROBACIÓN Y LEGITIMACIÓN. En este caso la aprobación es de dos tipos; la aprobación legalmente y la aprobación o aceptación ciudadana, es decir su legitimación. Jones $^{60}$, Anderson ${ }^{61}$ y Bardach $^{62}$, son claros al advertir que uno de los pasos más importantes es legitimar la política; recordemos que se trata de Estados democráticos donde la aprobación y legitimación de la alternativa pasa o debiera pasar por demás actores políticos y la propia población antes de ser implementada, si no, no se podrá ni debiera ser instrumentada y

60 JONES, Charles O. An Introduction of the Study of Public Policy. Belmont, California: Wadsworth Co., 1970.

${ }^{61}$ ANDERSON, James, Public Policy Making. New York: Rinehart y Winston, 1975.

62 BARDACH, E. Los ocho pasos para el análisis de Políticas Públicas: un manual para la práctica. México: CIDE, 2004. 
seleccionar entonces dentro de las otras, hasta el extremo incluso de desechar la posibilidad de una política pública. Obviamente aquí participan todos los actores: políticos, la opinión pública, la ciudadanía en general y gobernantes. Se puede considerar también como parte de la formulación, como se señaló y plantea al final del artículo (ver figura 3 anexa), aunque como se dijo, por su importancia es que quisimos resaltarla como algo singular y aparte. No obstante, la idea es la misma, y en ese orden, no pasa o debe pasar a la implementación, si antes no se aprueba y legitima la política.

APROBACIÓN Y LEGITIMACIÓN. No toda la política o decisión aprobada suele ser legitimada o aceptada por la población o el público (o lo público); pero al mismo tiempo, ninguna que sea legitimada debe ser implementada sin la aprobación de los gobiernos respectivos. Es decir, la aprobación (por parte del gobierno), no trae implícita una legitimación, pero ésta, tampoco debe condicionarla. Por eso es importante, que antes de su implementación, las políticas valoren el filtro de ambas y, es la sugerencia, que si no es susceptible a alguna de las dos, no sea implementada.

IMPLEMENTACIÓN. Esta etapa considera la implementación de la política, física (obras, programas y acciones, si fuera el caso) y normativamente; incluye una reprogramación y represupuestación (afinación o ajuste) de la alternativa seleccionada y sus programas y ejecución, con base a los tiempos, responsables y periodos de ejecución establecidos en la etapa de la formulación y, las metas y submetas medibles y cuantificables determinadas. Participan particularmente los responsables de la política, tanto en su ejecución, como en su implementación propiamente dicha. Es decir, los actores técnicos y los actores gubernamentales responsables. Los demás actores políticos y ciudadanos pudieran participar según se determine, de hecho, ha habido políticas que para su implementación incluyen la participación de la ciudadanía.

AFINACIÓN O AJUSTE. Considera la reprogramación, represupuestación y ajuste de la alternativa seleccionada, con base a los tiempos, metas, responsables y periodos de ejecución establecidos de origen $\mathrm{y} / \mathrm{o}$ ajustados.

EJECUCIÓN. Comprende la ejecución en sí de la política pública seleccionada.

SEGUIMIENTO Y CONTROL (LA EVALUACIÓN DURANTE). En un principio, se había considerado el seguimiento y evaluación, como una etapa más de la implementación, pero por considerarla precisamente como una parte esencial, acaso la más importante, la quisimos dejar 
aparte, como una parte autónoma e independiente, porque se considera que los actores que principalmente habrán o deberán de buscar que se lleve a cabo como fue concebida, no debe ser sólo el gobierno, sino los demás actores políticos y la sociedad en general, de hecho, recomendamos oficinas autónomas, sean gubernamentales o de la sociedad civil, para saber con certeza, si fue o no la solución a la problemática presentada. Hasta para permitirnos ajustarla, modificarla o incluso pararla. Ninguna política es infalible.

SEGUIMIENTO Y CONTROL. Tal vez para nosotros, y el modelo, ésta es la etapa más importante y nuestra propuesta: la evaluación durante, se puede valorar y formular acertadamente una política; que sea ésta aprobada y legitimada, pero si no se le da un seguimiento y control a su implementación, ciertamente estaremos en serios problemas. De hecho, la mayoría de las políticas es de lo que adolecen, de un seguimiento y control eficiente, lo que conlleva de antemano, un resultado incierto.

EVALUACIÓN FINAL. Esta etapa es la última más no ciertamente la final, dependerá precisamente del resultado; como se señaló anteriormente, se trata de contrastar los resultados con los indicadores medibles y cuantificables esperados y, dependiendo de ello, su finalización, terminación, adecuación o continuidad.

RESULTADOS. Se trata de valorar los resultados finales de la política implementada una vez concluida de acuerdo a las metas y resultados esperados, qué tanto se avanzó, respondió o solucionó el problema o la situación en cuestión.

FINALIZACIÓN DE LA POLÍTICA, CONCLUSIÓN, ADECUACIÓN O CONTINUIDAD. Aunque muchos autores coincidimos en que la política no termina, al menos si finaliza, tanto en fines prácticos como normativos, sobre todo, cuando no consigue resolver el problema para el cual fue diseñada e implementada o cuando no da el paso a una acción de Estado o permanente. Nuestro modelo considera el fin y terminación de la política cuando ha concluido su operación y cumplido para lo que fue diseñada. Sino, solamente finalizará, sobre todo sino ha conseguido el objetivo, aunque ciertamente pudiera ser readecuada o adaptada y, aún en los casos en que se ha conseguido el objetivo, servirá siempre de base o de know-how para situaciones futuras, de ahí también lo interminable. 


\section{CONCLUSIONES}

Ésta no es una propuesta sólo de elaboración de políticas públicas, sino de todo el proceso y como tal se presenta; de entrada, se propone que existen dos tiempos o momentos en su creación, interconectados por sus aprobaciones y legitimaciones: el del escritorio y el del campo; el de su elaboración y su implementación. Que irónicamente no tiene que ver necesariamente con su desarrollo, sino con su proceso (como se mencionó, puede existir una política pública que necesariamente no fue desarrollada en programas, proyectos o acciones sino con inacciones o decisión de no hacer algo ${ }^{63}$ ), si no hay aprobación o legitimación de las políticas aprobadas (aún las que no se llevarán a cabo), no hay política pública y no hay implementación; es necesario advertir también, que consideramos dos momentos de programación y presupuestación, uno de ellos en la formulación y otro, en la implementación, que llamamos precisamente por lo mismo reprogramación y represupuestación o de afinación o ajuste. Para nosotros, en estos casos, hay o debiera haber una conexión entre la formulación de la política y la implementación y ésta, debe de ser la programación y presupuestación, el conector por cierto no sólo de las dos etapas, sino de los dos tiempos contemplados, los dos escenarios, el del escritorio y el del campo. Vale para advertir también, que no pueden o deben implementarse políticas que no "fueron" programadas (y/o presupuestadas), aún las no realizadas con acciones físicas o específicas ${ }^{64}$. La formulación, debe anteceder al presupuesto y no al revés, en el escenario que sea; al presupuesto anual incluso, nos podemos referir.

Hemos marcado también por lo mismo, y así se debe de entender, tres etapas antes y tres etapas posteriores al presupuesto y/o la presupuestación: el nacimiento, la valoración y formulación y, la aprobación y legitimación (que como dijimos podría considerarse como parte de la formulación, pero que aquí la quisimos proponer aparte, incluso como un proceso más) y; la implementación, el control y la evaluación final. Uno de ellos, el de aprobación y legitimación, al mismo tiempo como conector, sino hay política aprobada o legitimada no hay o debiera haber política. Esta es la política pública verdadera. No se desconoce que pueden suceder y suceden políticas públicas o acciones responsivas y/o reactivas durante el gobierno que deben ser atendidas sin retardo, que debieran ser las menos, por cierto, pero, aun así, el caso sería el mismo. Incluso, es necesario y hasta obligatorio, se mencionó, establecer por parte

63 DYE, Thomas R. Understanding Public Policies. New Jersey: Pearson Prentice Hall, 2008.
64 DYE, Thomas R. Understanding Public Policies. New Jersey: Pearson Prentice Hall, 2008. 
del gobierno un área especializada, ciudadana u oficial, pero autónoma, que lleve a cabo puntual y oportunamente esta evaluación y seguimiento de las políticas implementadas y sus acciones.

Otros elementos para considerar son la participación democrática, que se dijo, debiera ser considerada e impulsada desde el momento mismo de su nacimiento y, en las diferentes etapas por cierto de la política desarrollada, así como la cabal detección del problema, que estribe en las verdaderas causas y no en los efectos.

Consideramos que estas "lagunas" y algunas otras, son importantes de solucionar y trabajar en ellas, de lo contrario, seguiremos abonando a tratar de resolver problemas que no se solucionarán y seguirán ahondándose en la insuficiencia de los que están, o estamos obligados a resolverlos. Ciertamente, se hizo notar que las políticas públicas no siempre responden a intenciones de desarrollar el Estado, cual debiera ser, sino a conservar el poder; no obstante, también se dijo, partimos de un estado ideal de las políticas públicas, que no obvia lo otro, sino lo concurre y que, en el peor de los casos, servirá de algún modo.

\section{REFERENCIAS}

AGUILAR Astorga, Carlos; LIMA F., Marco Antonio. ¿Qué son y para qué sirven las Políticas Públicas?, en Contribuciones a las Ciencias Sociales, septiembre 2009. Disponible en: www.eumed.net/rev/cccss/05/aalf.htm. Accesado el: 10 jul. 2018.

AGUILAR Villanueva, L. Antologías de Política Pública. México: Porrúa, 1993.

AGUILAR Villanueva, L. Estudio Introductorio. In: VILLANUEVA, Luis Aguilar. La Hechura de las Políticas Públicas. México: Miguel Ángel Porrúa, 1996. p. 15-84.

ANDERSON, James, Public Policy Making. New York: Rinehart y Winston, 1975.

BARDACH, E. Los ocho pasos para el análisis de Políticas Públicas: un manual para la práctica. México: CIDE, 2004.

BREWER, Garry. The Policy Sciences Emerge: To Nurture and Structure a Discipline. In: Policy Sciences, v. 5, v. 3. 1974. p. 139-244.

BRUM, Cardozo M. La evaluación de políticas y programas públicos: el caso de los programas de desarrollo social en México. México: Porrúa, 2006.

CANTO, M. Introducción a las políticas públicas. In: Manuel Canto; O. Castro (Orgs).

Participación Ciudadana y Políticas Públicas en el Municipio. México: MCD, 2002 
CATALÁ, Daniel. Las políticas públicas y su ciclo. Disponible en:

https: / / totaleval.wordpress.com/2015/02/11/las-politicas-publicas-y-su-ciclo/. Accesado el: 15 ago. 2019

DYE, Thomas R. Understanding Public Policies. New Jersey: Pearson Prentice Hall, 2008.

FLORES CÁCERES, Tito. Definición de política pública: una revisión conceptual. Disponible en: https: / politicapublica.cl/2014/11/10/definicion-de-politica-publica-revision-conceptual/. Accesado el: 8 jun. 2017.

FERNÁNDEZ, Antoni. Las Políticas Públicas. In: CAMINAL, Miguel. Manual de Ciencia Política. Madrid: Tecnos, 1999. p. 460-482.

GRAU, Mireia. Introducción. El Estudio de las Políticas Públicas: Enfoques y Metodologías de Análisis. In: M. Grau; A. Mateos. Análisis de Políticas Públicas en España: enfoques y casos, Valencia: Tirant lo Blanch, 2002. p. 29-58.

HECLO, Hugh; WILDAVSKY, Aaron. The Private Government of Public Money. London: Macmillan, 1977.

HOWLETT, Michael; RAMESH, M. Studying Public Policy: Policy Cycles and Policy Subsistems. Canadá: Oxford University Press, 1995.

JAIME, Fernando, et al. Introducción al análisis de políticas públicas. Argentina: Universidad Nacional Arturo Jauretche, 2013. p. 85-118.

JENKINS, William. Policy Analysis: A Political and Organizational Perspective. London: Martin Robertson, 1978.

JONES, Charles O. An Introduction of the Study of Public Policy. Belmont, California: Wadsworth Co., 1970.

KRAFT, Michael; FURLONG, Scott. Public Policy: Politics, Analysis and Alternatives. Washington DC: CQ Press, 2006.

LASSWELL, H. La concepción emergente de las ciencias de políticas. In: Luis Aguilar V. El estudio de las políticas públicas. México: Porrúa, 1992. p. 79-117.

LAHERA, Eugenio. Introducción a las Políticas Públicas. Santiago de Chile: Fondo de Cultura Económica, 2002.

LINDBLOM, Charles. Usable knowledge: Social science and social problem solving. USA: Yale University Press, 1979.

MAJONE, Giandomenico. Evidence, Argument \& Persuasion in the Policy process. New Haven: Yale University Press, 1989.

MAY, Judith; WILDAVSKY, Aaron. The Policy Cycle. Beverly Hills: Sage, 1978. 
MEDELLIN, P. La política de las políticas públicas: propuesta teórica y metodológica para el estudio de las políticas públicas en países de frágil institucionalidad. Chile: Serie Políticas Sociales, n. 93, 2004.

MENY, Y.; THOENING, J. Las Políticas Públicas. Barcelona: Editorial Ariel, 1992.

PLANO, Jack C. Political Science Dictionary. Michigan: Dryden Press, 1973.

ROSE, Richard. Comparing Public Policy: An Overview. In: European Journal of Political Research, v. 1, v. 1, 1973. p. 67-94.

ROTH, A. Políticas Públicas: Formulación, Implementación y Evaluación. Bogotá: Aurora, 2006.

SUBIRATS, J.; GOMÁ, R. Democratización, Dimensiones de Conflicto y Políticas Públicas en España. In: Ricard Gomá y Joan Subirats (Orgs). Políticas Públicas en España. Contenidos, Redes de Actores y Niveles de Gobierno. España: Ariel Ciencia Política, 1998. p. 13-36.

TAMAYO Sáenz, Manuel. El análisis de las políticas públicas. In: Rafael Bañón y Ernesto Castillo (Orgs). La nueva administración pública. Madrid: Alianza editorial, 1997. p. 281-312. 


\section{ANEXOS}

\section{DEFINICIONES SOBRE POLÍTICAS PÚBLICAS}

\section{COMO ELEMENTO POLÍTICO}

\begin{tabular}{|l|l|}
\hline \multicolumn{1}{|c|}{ AUTOR } & \multicolumn{1}{c|}{ DEFINICIÓN } \\
\hline GRAU (2002) & $\begin{array}{l}\text { Son el conjunto de acciones, de procesos, de interacciones e } \\
\text { intercambios entre actores que tienen lugar en los ámbitos del } \\
\text { poder político. }\end{array}$ \\
\hline JENKINS (1978) & $\begin{array}{l}\text { Un conjunto de decisiones interrelacionadas, tomadas por uno o } \\
\text { varios actores políticos. }\end{array}$ \\
\hline MANUEL CANTO (2002) & $\begin{array}{l}\text { Cursos de acción tendientes a la solución de problemas públicos, } \\
\text { definidos a partir de la interacción de diversos sujetos sociales, } \\
\text { en medio de una situación de complejidad social y de relaciones } \\
\text { de poder, que pretenden utilizar de manera más eficiente los } \\
\text { recursos públicos y tomar decisiones a través de mecanismos } \\
\text { democráticos, con la participación de la sociedad. }\end{array}$ \\
\hline ROTH (2006) & $\begin{array}{l}\text { Tiene tres acepciones (políticas): la política, concebida como el } \\
\text { ámbito del gobierno de las sociedades humanas (polity). La } \\
\text { política como la actividad de organización y lucha por el control } \\
\text { del poder (politics). Y, la política como designación de los } \\
\text { propósitos y programas de las autoridades públicas (policy). }\end{array}$ \\
\hline MEDELLIN (2004) & $\begin{array}{l}\text { Producto de un intenso proceso político a través del cual } \\
\text { emergen y toman forma los proyectos e intereses de agentes } \\
\text { (individuos), agencias (instituciones) y discursos (síntesis de la } \\
\text { interacción entre agentes y agencias) en pugna por imponer un } \\
\text { determinado proyecto de dirección política y de dirección } \\
\text { ideológica sobre la sociedad y el estado que son gobernados. }\end{array}$ \\
\hline
\end{tabular}

\section{COMO ELEMENTO GUBERNAMENTAL}

\begin{tabular}{|l|l|}
\hline \multicolumn{1}{|c|}{ AUTOR } & \multicolumn{1}{|c|}{ DEFINICIÓN } \\
\hline DYE (2008) & Es todo lo que los gobiernos deciden hacer o no hacer. \\
\hline MENY Y THOENIG (1992) & $\begin{array}{l}\text { Es el resultado de la actividad de una autoridad investida de } \\
\text { poder público y de legitimidad gubernamental. }\end{array}$ \\
\hline TAMAYO (1997) & $\begin{array}{l}\text { Son el conjunto de objetivos, decisiones y acciones que lleva a } \\
\text { cabo un gobierno para solucionar los problemas que en un } \\
\text { momento determinado los ciudadanos y el propio gobierno } \\
\text { consideran prioritarios. }\end{array}$ \\
\hline LASWELL (1971) & $\begin{array}{l}\text { Disciplinas que se ocupan de explicar los procesos de } \\
\text { elaboración y ejecución de las políticas, con base científica, } \\
\text { interdisciplinaria y al servicio de gobiernos democráticos }\end{array}$ \\
\hline BRUM (2006) & $\begin{array}{l}\text { Fenómeno social, administrativo y político, resultado de un } \\
\text { proceso de sucesivas tomas de posición, que se concretan en un } \\
\text { conjunto de decisiones, acciones u omisiones, asumidas } \\
\text { fundamentalmente por los gobiernos }\end{array}$ \\
\hline HECLO Y WILDAVSKY (1975) & $\begin{array}{l}\text { Una acción gubernamental dirigida hacia el logro de objetivos } \\
\text { fuera de ella misma. }\end{array}$ \\
\hline
\end{tabular}




\begin{tabular}{|l|l|}
\hline GRACAS (2006) & Conjunto de decisiones que se traducen en acciones, \\
& estratégicamente seleccionadas. Su dimensión es pública por el \\
& tamaño del agregado social sobre el cual coinciden, pero sobre \\
& todo, por su carácter gubernamental.
\end{tabular}

\section{COMO ELEMENTO ADMINISTRATIVO}

\begin{tabular}{|l|l|}
\hline \multicolumn{1}{|c|}{ AUTOR } & \multicolumn{1}{|c|}{ DEFINICIÓN } \\
\hline AGUILAR VILLANUEVA (1996) & $\begin{array}{l}\text { a) El diseño de una acción colectiva intencional, b) el curso que } \\
\text { efectivamente toma la acción como resultado de las muchas } \\
\text { decisiones e interacciones que comporta y, c) los hechos reales } \\
\text { que la acción colectiva produce. }\end{array}$ \\
\hline PLANO (1973) & $\begin{array}{l}\text { Reglamentos y programas gubernamentales considerados } \\
\text { individualmente o en su conjunto, esto es, los productos de las } \\
\text { decisiones de autoridad de un sistema político. }\end{array}$ \\
\hline
\end{tabular}

\section{COMO ELEMENTO DEMOCRÁTICO}

\begin{tabular}{|l|l|}
\hline \multicolumn{1}{|c|}{ AUTOR } & \multicolumn{1}{|c|}{ DEFINICIÓN } \\
\hline LAHERA (2002) & $\begin{array}{l}\text { Corresponde a cursos de acción y flujos de información } \\
\text { relacionados con un objetivo público definido en forma } \\
\text { democrática. }\end{array}$ \\
\hline LASWELL (1971) & $\begin{array}{l}\text { Disciplinas que se ocupan de explicar los procesos de } \\
\text { elaboración y ejecución de las políticas, con base científica, } \\
\text { interdisciplinaria y al servicio de gobiernos democráticos }\end{array}$ \\
\hline CANTO (2002) & $\begin{array}{l}\text { Cursos de acción tendientes a la solución de problemas públicos, } \\
\text { definidos a partir de la interacción de diversos sujetos sociales, } \\
\text { en medio de una situación de complejidad social y de relaciones } \\
\text { de poder, que pretenden utilizar de manera más eficiente los } \\
\text { recursos públicos y tomar decisiones a través de mecanismos } \\
\text { democráticos, con la participación de la sociedad. }\end{array}$ \\
\hline
\end{tabular}

\section{OTRAS DEFINICIONES}

\begin{tabular}{|l|l|}
\hline \multicolumn{1}{|c|}{ AUTOR } & \multicolumn{1}{|c|}{ DEFINICIÓN } \\
\hline FERNÁNDEZ (1999) & $\begin{array}{l}\text { No es un fenómeno objetivo de perfiles claros y definidos, su } \\
\text { existencia debe ser puesta de relieve como fruto de la } \\
\text { investigación en el plano empírico mediante la identificación de } \\
\text { sus elementos constitutivos, sean estos declaraciones de } \\
\text { intenciones, programas, decisiones. }\end{array}$ \\
\hline KRAFT Y FURLONG (2006) & $\begin{array}{l}\text { Es un curso de acción o de inacción gubernamental, en respuesta } \\
\text { a problemas públicos. Reflejan no sólo los valores más } \\
\text { importantes de una sociedad, sino que también el conflicto } \\
\text { entre valores. Dejan de manifiesto a cuál de los valores se le } \\
\text { asigna la más alta prioridad en una determinada decisión. }\end{array}$ \\
\hline MAHONE (1989) & $\begin{array}{l}\text { Está hecha de lenguaje. Sea en su forma oral o escrita, el } \\
\text { debate, la argumentación, son centrales en todas las etapas del } \\
\text { proceso de las políticas públicas. }\end{array}$ \\
\hline SUBIRATS Y GOMÁ (1998) & Las políticas deben considerarse como propuestas de regulación \\
\hline
\end{tabular}




\begin{tabular}{|l|l|}
\hline & $\begin{array}{l}\text { pública de los múltiples problemas y contradicciones que } \\
\text { afrontan las sociedades actuales. }\end{array}$ \\
\hline CANTO (2002) & $\begin{array}{l}\text { Cursos de acción tendientes a la solución de problemas públicos, } \\
\text { definidos a partir de la interacción de diversos sujetos sociales, } \\
\text { en medio de una situación de complejidad social y de relaciones } \\
\text { de poder, que pretenden utilizar de manera más eficiente los } \\
\text { recursos públicos y tomar decisiones a través de mecanismos } \\
\text { democráticos, con la participación de la sociedad. }\end{array}$ \\
\hline LINDBLOM (1979) & $\begin{array}{l}\text { Procesos, decisiones y resultados, pero sin que ello excluya } \\
\text { conflictos entre intereses presentes en cada momento, tensiones } \\
\text { entre diferentes definiciones del problema a resolver, entre } \\
\text { diferentes racionalidades organizativas y de acción, y entre } \\
\text { diferentes perspectivas. }\end{array}$ \\
\hline
\end{tabular}

Fuente: elaboración propia

Figura 3

\section{ETAPAS Y FASES DE LAS POLÍTICAS PÚBLICAS}

\section{I) PROCESO DE ELABORACIÓN}

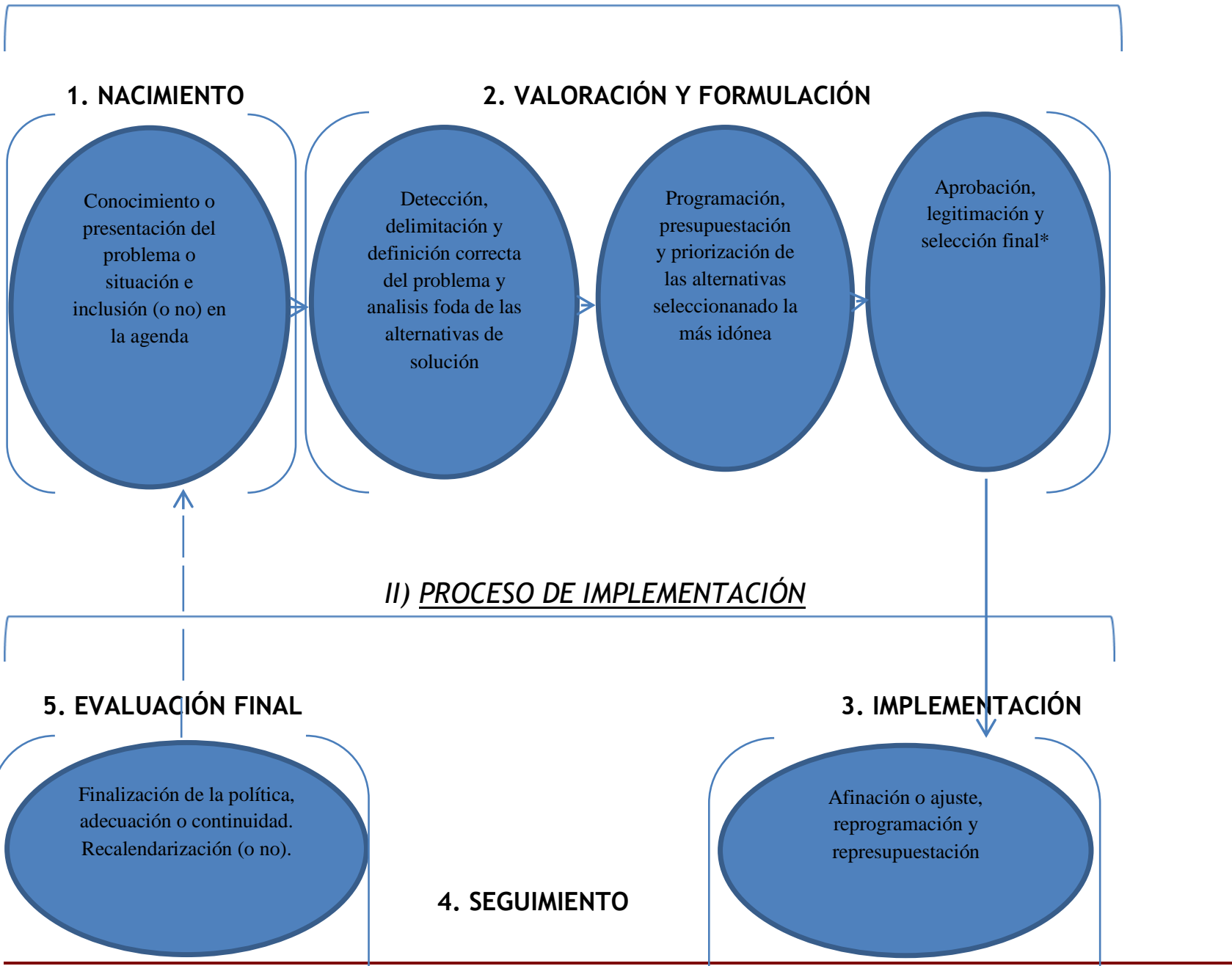

Revista Eletrônica do Curso de Direito da UFSM www.ufsm.br/revistadireito 


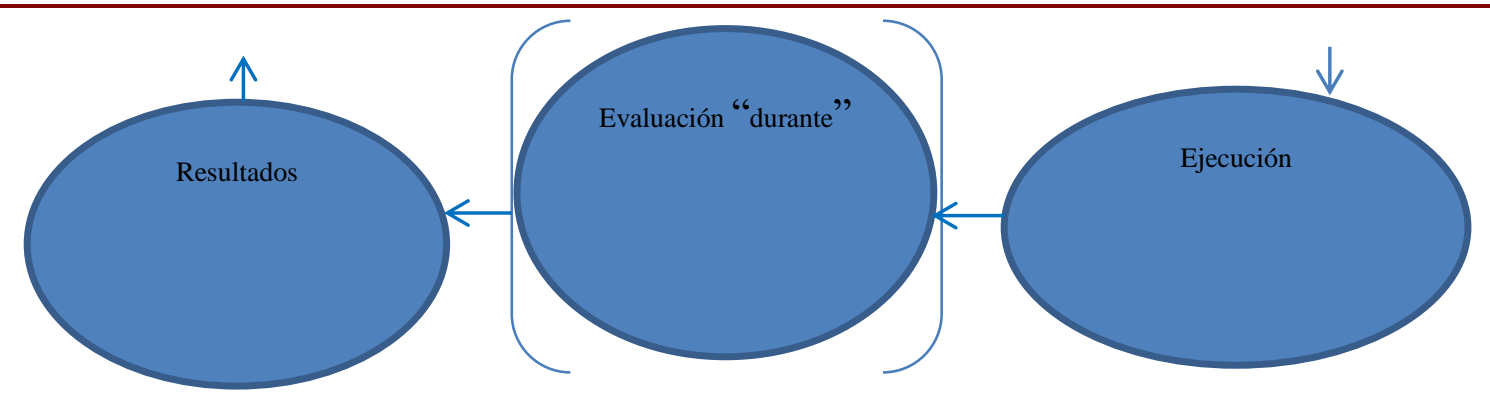

Fuente: elaboración propia

* Se podría considerar el proceso de aprobación y legitimación incluido en la etapa de Formulación.

Artigo convidado / Publicado em: 26.06.2020

\section{COMO FAZER REFERÊNCIA AO ARTIGO (ABNT):}

EDEZA, Manuel Ángel Rodríguez. La evaluación durante: el corazón de las políticas públicas hacia un modelo general para la creación de políticas públicas. Revista Eletrônica do Curso de Direito da UFSM, Santa Maria, RS, v. 15, n. 1, e47071, jan./abr. 2020. ISSN 1981-3694. DOI:

http://dx.doi.org/10.5902/1981369447071. Disponível em:

https://periodicos.ufsm.br/revistadireito/article/view/47071 Acesso em: dia mês. ano.

Direitos autorais 2020 Revista Eletrônica do Curso de Direito da UFSM

Editores responsáveis: Rafael Santos de Oliveira e Angela Araujo da Silveira Espindola

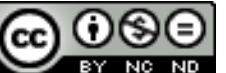

Esta obra está licenciada com uma Licença Creative Commons Atribuição-NãoComercial-SemDerivações 4.0 Internacional.

\section{SOBRE O AUTOR}

\section{MANUEL ÁNGEL RODRÍGUEZ EDEZA}

Doutor em Ciências Sociais pela Universidad Autónoma de Sinaloa. Economista y polítólogo, Profesor Investigador por la Universidad Autónoma de Occidente, México. Departamento de Gobierno y Administración. Economista y politólogo. 